\title{
Article \\ Dysbiosis Triggers ACF Development in Genetically Predisposed Subjects
}

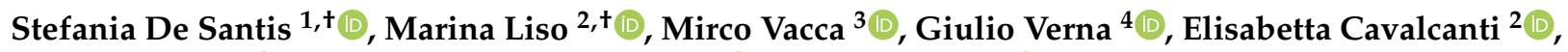 \\ Sergio Coletta ${ }^{2}\left(\mathbb{D}\right.$, Francesco Maria Calabrese ${ }^{3}\left(\mathbb{D}\right.$, Rajaraman Eri $\left.{ }^{5}{ }^{(}\right)$, Antonio Lippolis ${ }^{2}$, Raffaele Armentano ${ }^{2}$, \\ Mauro Mastronardi ${ }^{2}$, Maria De Angelis ${ }^{3, *}$ and Marcello Chieppa ${ }^{2, *}$ (i)
}

1 Department of Pharmacy-Drug Science, University of Bari Aldo Moro, 70126 Bari, Italy; stefania.desantis@uniba.it

2 Research Department, National Institute of Gastroenterology “S. de Bellis", Research Hospital, 70013 Castellana Grotte, Italy; marinaliso@libero.it (M.L.); elisabetta.cavalcanti@irccsdebellis.it (E.C.); sergiofalaut@hotmail.it (S.C.); antonio.lippolis@irccsdebellis.it (A.L.); raffaele.armentano@irccsdebellis.it (R.A.); mauro.mastronardi@irccsdebellis.it (M.M.)

3 Department of Soil, Plant and Food Sciences, University of Bari, 70126 Bari, Italy; mirco.vacca@uniba.it (M.V.); francesco.calabrese@uniba.it (F.M.C.)

4 Department of Pharmacy, University of Salerno, 84084 Fisciano, Italy; gverna@unisa.it

5 School of Health Sciences, College of Health and Medicine, University of Tasmania, Launceston, TAS 7250, Australia; rajaraman.eri@utas.edu.au

* Correspondence: maria.deangelis@uniba.it (M.D.A.); marcello.chieppa@irccsdebellis.it (M.C.); Tel.: +39-080-544-2949 (M.D.A.); +39-080-499-4628 (M.C.)

+ These authors equally contributed to the paper.

check for

updates

Citation: De Santis, S.; Liso, M.; Vacca, M.; Verna, G.; Cavalcanti, E.; Coletta, S.; Calabrese, F.M.; Eri, R.; Lippolis, A.; Armentano, R.; et al. Dysbiosis Triggers ACF Development in Genetically Predisposed Subjects. Cancers 2021, 13, 283. https:// doi.org/10.3390/cancers13020283

Received: 3 December 2020 Accepted: 8 January 2021

Published: 14 January 2021

Publisher's Note: MDPI stays neutral with regard to jurisdictional clai$\mathrm{ms}$ in published maps and institutional affiliations.

Copyright: (C) 2021 by the authors. Licensee MDPI, Basel, Switzerland. This article is an open access article distributed under the terms and conditions of the Creative Commons Attribution (CC BY) license (https:// creativecommons.org/licenses/by/ $4.0 /)$.
Simple Summary: Colorectal cancer (CRC) is a non-communicable disease resulting from the combination of a genetic predisposition and environmental triggers, possibly including intestinal microbiota composition. However, the relationship between microbiota modulation and other CRC risk factors is still debated. With the intent to shed light on the axis between microbial imbalance and ACF (aberrant crypt foci) development in genetically predisposed individuals, we used the Winnie$\mathrm{APC}^{\mathrm{Min} /+}$ model combining genetics and inflammation. Our results indicate that the mother's microbial composition can be a transmittable risk factor favoring the cascade of events finally resulting in ACF development in the offspring. In light of these results, preventive strategies developed to avoid dysbiosis could help to reduce the risk of tumor lesion onset and progression. These preventive approaches may be particularly effective during pregnancy and lactation to reduce a child's risk of CRC development.

Abstract: Background: Colorectal cancer (CRC) is the third most common cancer worldwide, characterized by a multifactorial etiology including genetics, lifestyle, and environmental factors including microbiota composition. To address the role of microbial modulation in CRC, we used our recently established mouse model (the Winnie-APC ${ }^{\mathrm{Min} /+}$ ) combining inflammation and genetics. Methods: Gut microbiota profiling was performed on 8-week-old Winnie-APC ${ }^{\mathrm{Min} /+}$ mice and their littermates by $16 \mathrm{~S}$ rDNA gene amplicon sequencing. Moreover, to study the impact of dysbiosis induced by the mother's genetics in ACF development, the large intestines of $\mathrm{APC}^{\mathrm{Min} /+}$ mice born from wild type mice were investigated by histological analysis at 8 weeks. Results: ACF development in 8-week-old Winnie-APC ${ }^{\mathrm{Min} /+}$ mice was triggered by dysbiosis. Specifically, the onset of ACF in genetically predisposed mice may result from dysbiotic signatures in the gastrointestinal tract of the breeders. Additionally, fecal transplant from Winnie donors to $\mathrm{APC}^{\mathrm{Min} /+}$ hosts leads to an increased rate of ACF development. Conclusions: The characterization of microbiota profiling supporting CRC development in genetically predisposed mice could help to design therapeutic strategies to prevent dysbiosis. The application of these strategies in mothers during pregnancy and lactation could also reduce the CRC risk in the offspring.

Keywords: colorectal cancer; microbiota; dysbiosis; ulcerative colitis; murine model 


\section{Introduction}

Colorectal cancer (CRC) is the third most common cancer with an incidence and mortality rate rapidly increasing worldwide, particularly in industrialized countries [1]. Due to the multifactorial nature of CRC, several risk factors have been identified, i.e., genetics, environment, and lifestyle [2]. Overall, these risk factors result in an increased chronic inflammatory state leading to cancer development, in accordance with the inclusion of inflammation as the seventh hallmark feature of cancer [3]. Therefore, numerous studies have established the negative impact of a sedentary lifestyle and dietary regimens enriched in processed foods and animal fat in association with a low fiber intake [4]. Moreover, the beneficial role of healthy compounds from fruits and vegetables is well established for intestinal disorders [5,6] as well as for other inflammatory conditions [7-9].

Increasing data demonstrate that all CRC risk factors, including diet, could modulate the gut microbiota, a community of microorganisms (i.e., bacteria, virus, fungi, archaea, and protist) colonizing our gastrointestinal tract [10]. This complex ecosystem is considered an active organ able to interact with the host and which is directly involved in various processes, such as tissue development, nutritional absorption, metabolism, and immunity [11]. Imbalance in the gut microbiome, called dysbiosis, is associated with numerous human diseases, including cancer $[12,13]$. Hence, the microbiome involvement in the pathogenesis of cancer has also been recognized for CRC $[14,15]$. It is widely accepted that CRC patients are depleted in bacteria producing short chain fatty acids (SCFAs), metabolites that contribute to preserving intestinal homeostasis [16,17]. Moreover, in CRC patients an enrichment in pro-inflammatory bacterial taxa, as well as those producing toxins, has been observed, causing direct damage to gut cells. Among these, some strains could produce enterotoxins that, in combination with reactive oxygen species, cause oxidative DNA damage, epithelial barrier disruption, and inflammation $[18,19]$. In CRC development, the $\beta$-catenin signaling plays a pivotal role in inducing cellular proliferation. In this line, different bacterial species have been found to be able to activate $\beta$-catenin signaling (e.g., Bacteroides fragilis and Fusobacterium nucleatum) $[20,21]$. Moreover, an increase in cellular proliferation could also be related to the genotoxin colibactin produced by the pks+ E. coli strains reporting the polyketide synthase gene complex (pks) gene [22]. On the contrary, the decrease in SCFA detection is mainly related to low abundances (up to a lack) of butyrogenic bacteria, such as Lachnospiraceae, Ruminococcaceae, Bifidobacteriaceae, Lactobacillaceae, and specific species, such as Faecalibacterium prausnitzii [23-26].

However, the microbiota profile in CRC is not universally valid, suggesting a synergistic action of both harmful and protective bacteria in colonic tumor initiation and/or progression. This synergy is also supported by the "driver-passenger theory" in which bacterial drivers (indigenous intestinal bacteria) act as first triggers that promote cancer initiation [27]. Later, the ongoing tumorigenesis induces changes in the surrounding microenvironment, allowing a competitive advantage for opportunistic bacteria (defined as bacterial passengers) able to enforce tumor progression. The "driver-passenger theory" suggests that bacterial drivers and passengers have distinct temporal associations with CRC development, and therefore they could have distinct roles in CRC pathogenesis [27].

In general, several studies report a different composition in terms of gut microbiota between stool samples from CRC patients and control subjects, as well as from tumor and adjacent non-tumor mucosa in patients with CRC [28,29]. Moreover, changes in gut microbiota have been reported for all stages of CRC development from adenomatous polyps to early-stage cancer to metastatic disease [30-32]. This could be particularly important considering a hypothetical use of specific microbial patterns as biomarkers for an early detection of CRC, with the aim to improve screening strategies. In addition, gut microbiota can also influence the efficacy or toxicity of therapy in CRC [33]. In this line, considering the promoting and supporting role of gut microbiota in CRC tumorigenesis, several strategies able to specifically target pro-tumoral bacteria have been developed. Among these, antibiotics indirectly affect CRC progression modulating the gut microbiota, even if their use generally has broad effects facilitating the acquisition of drug resistance. 
In addition, fecal microbiota transplantation (FMT), first described for Clostridium difficile infection (CDI) treatment [34], stands out as a promising strategy in the treatment of CRC patients, even if potential risks such as the selection of donors and recipients and the establishment of a tolerable dose and frequency are still debated concerning FMT in CRC, as well as in other diseases [35].

The actual knowledge about gut microbiota modulation in CRC tumorigenesis derives from numerous clinical and preclinical studies. Specifically, in genetic mouse models of CRC, such as $\mathrm{APC}^{\mathrm{Min} /+}$ mice [36,37], as well as in the commonly used model of colitisassociated CRC (CAC), i.e., the AOM/DSS model [38,39], the role of bacteria in the initiation and promotion of CRC has been extensively demonstrated. However, a CRC mouse model giving an integrated view on the impact of genetics and inflammation in terms of gut microbiota modulation is still missing.

For this reason, taking advantage of our recently established mouse model (the Winnie$\mathrm{APC}^{\mathrm{Min} /+}$ model) [40] that combines both an inflammatory background (Winnie mice) [41] and a genetic predisposition to develop small intestinal polyposis (APC $\mathrm{Min} /+^{+}$mice), in the present study we performed gut microbiota profiling to identify bacterial patterns supporting CRC tumorigenesis in genetically predisposed mice. In fact, Winnie mice, due to a single missense mutation (G9492A, GenBank accession no. AJ511872) in the Mucin 2 (Muc2) gene, can be considered as a low-grade, spontaneous, and progressive model of ulcerative colitis (UC) [41,42]. Moreover, we aim to study the genetics impact of Winnie ${ }^{+/-}$ breeders dictating a dysbiotic state on the aberrant crypt foci (ACF) development in $\mathrm{APC}^{\mathrm{Min} /+}$ puppies. This concept may introduce the paradigm of CRC as a communicable disease that spreads from mothers to child via intestinal microbiota transfer.

\section{Results}

2.1. Intestinal Microbiota in Winnie-APC Min/+ Mice Shows Dysbiotic Features Typical of Winnie Mice

To identify the microbial profiling promoting CRC development, we evaluated the microbiota of Winnie-APC $\mathrm{Min} /+$ mice and their littermates obtained from breeders in a heterozygous state for the Winnie mutation (for male and female) plus the APC ${ }^{\mathrm{Min} /+} \mathrm{mu}-$ tation (only for male) [40]. Gene amplicon sequencing analysis of fecal material collected from 8-week-old mice reported 28,301.18 $\pm 17,409.02$ number of reads per sample. The percentage $89.09 \pm 2.12$ of total reads per sample was assigned at least to the genus level. Microbial differences among Winnie-APC $\mathrm{Min} /+$ mice and their littermates have been evaluated. Analysis of $\alpha$-diversity showed significant differences for Shannon index comparing Winnie to $\mathrm{APC}^{\mathrm{Min} /+}$ and Winnie-APC ${ }^{\mathrm{Min} /+}$ samples $(p=0.0286)$ as well as in OTU (operational taxonomic unit) number comparing Winnie to Winnie-APC ${ }^{\mathrm{Min} /+}$ mice $(p=0.0167)$ (Supplementary Materials Table S1). At the phylum level (Figure 1), Winnie-APC ${ }^{\mathrm{Min} /+}$ mice (Wi_APCMin) reported high abundances of Verrucomicrobia. Winnie mice (Wi) did not show the same significant association in Verrucomicrobia abundance, whereas both Winnie-APC ${ }^{\mathrm{Min} /+}$ and Winnie reported a significant reduction in Deferribacteres and Proteobacteria abundances than wild type (WT) and $\mathrm{APC}^{\mathrm{Min} /+}$ mice (APCMin) $(p \leq 0.002$; $q \leq$ 0.012; Table 1). Concerning Firmicutes to Bacteroidetes ratios, we observed a significant reduction in Winnie-APC ${ }^{\mathrm{Min} /+}$ mice compared to WT mice $(p=0.0181$, Figure S1). Bacterial families that mainly characterized Winnie-APC ${ }^{\mathrm{Min} /+}$ mice were Acholeplasmataceae, Bacteroidaceae, some members of Clostridiaceae (specifically clostridia not belonging to the Clostridium cluster I), Eubacteriaceae, Prevotellaceae, and Verrucomicrobiaceae $\left(p \leq 0.005 ; q \leq 0.019\right.$; Table 1 and Figure S2). Conversely, Winnie-APC ${ }^{\mathrm{Min} /+}$ mice reported a significant negative association with abundances of Clostridiaceae (cluster I), Coriobacteriaceae, Deferribacteraceae, Helicobacteraceae, and Lactobacillaceae $(p \leq 0.005 ; q \leq 0.021$; Table 1). Similarly to Winnie-APCMin/+, Winnie mice reported a positive association with Acholeplasmataceae, Clostridiaceae (not belonging to the Clostridium cluster I), and Eubacteriaceae abundances $(p \leq 0.001 ; q \leq 0.004)$ and a negative association with Deferrib- 
acteraceae and Helicobacteraceae $(p \leq 0.001 ; q \leq 0.004$; Table 1). Only Winnie mice reported a negative association to Enterobacteriaceae abundances $(p=0.004 ; q=0.017$; Table 1$)$.

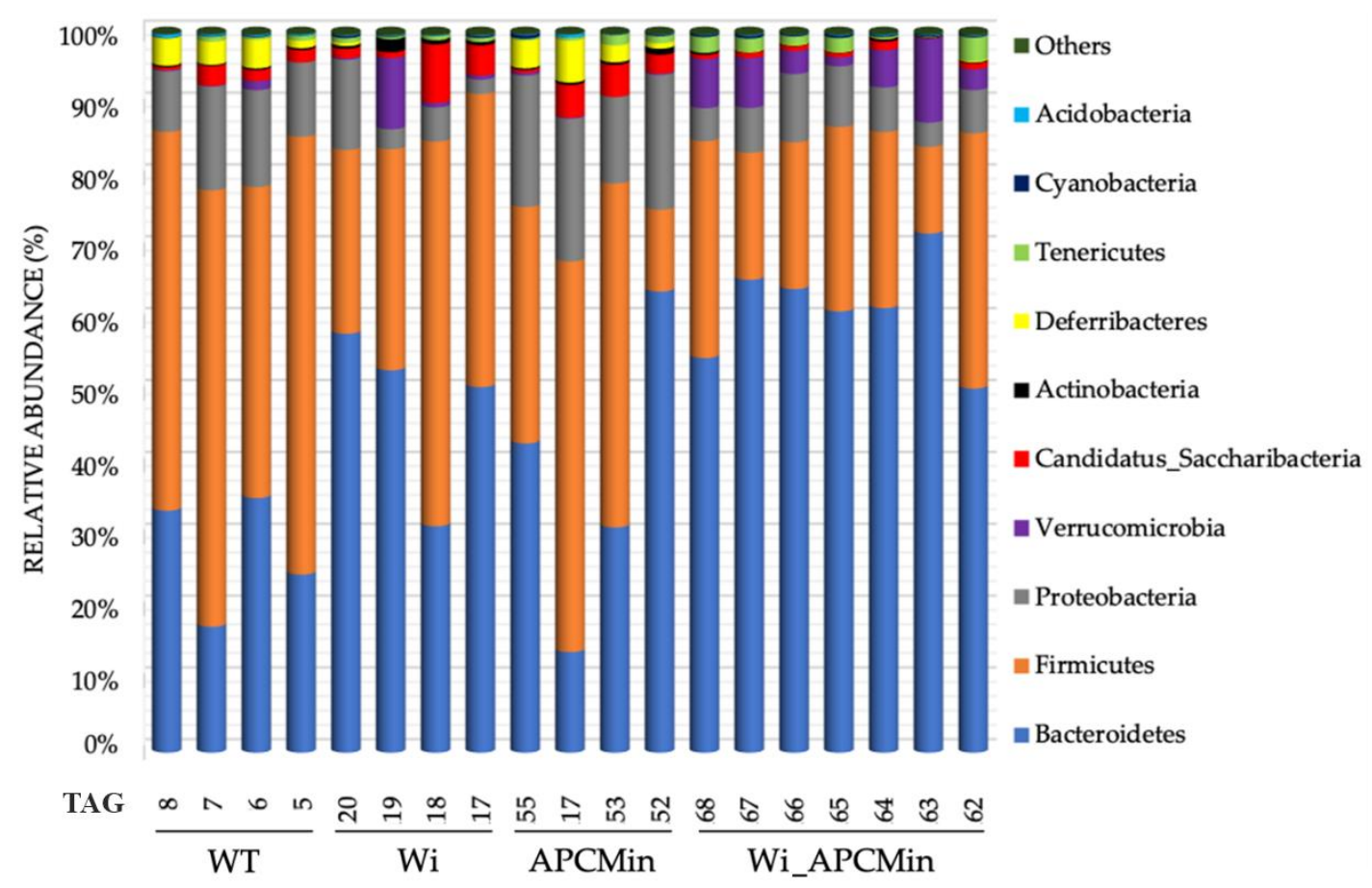

Figure 1. Gut microbiota profiling at phylum level of 8-week-old Winnie-APC ${ }^{\mathrm{Min} /+}$ mice (Wi_APCMin) and their control littermates. Ear TAGs of each mouse for all the experimental groups are indicated. Abbreviations: WT, wild type-C57BL/6J mice; Wi, Winnie mice; APCMin, $\mathrm{APC}^{\mathrm{Min} /+}$ mice.

As observed in Table 1, the principal component analysis (PCA), performed using as variables all bacterial families with a relative abundance $>1 \%$ at least in one sample, also showed a partial overlapping of Winnie-APC $\mathrm{Min} /+$ and Winnie gut microbiota (Figure 2). Differences occurring between these two groups were related to Bacteroidaceae, Prevotellaceae, and Verrucomicrobiaceae abundances, mainly characterizing Winnie-APC ${ }^{\mathrm{Min} /+}$ rather than Winnie mice (Figure 2; Table 1). The negative association with Coriobacteriaceae and Lactobacillaceae was significantly found only in Winnie-APC Min/+ mice (Figure 2; Table 1). Meanwhile, the afore reported negative association with Proteobacteria was specifically related to Clostridiaceae (cluster I) abundances in Winnie-APC ${ }^{\mathrm{Min} /+}$ mice and to Enterobacteriaceae abundances in Winnie mice (Figure 2; Table 1). 


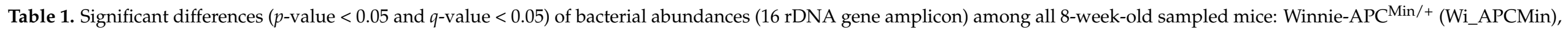

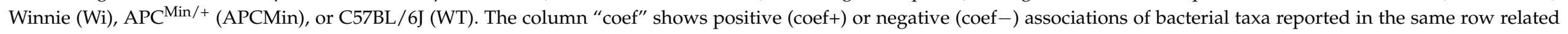

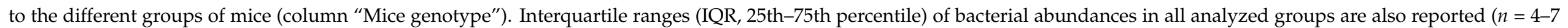
animals/group).

\begin{tabular}{|c|c|c|c|c|c|c|c|c|c|}
\hline & $\begin{array}{c}\text { Mice } \\
\text { Genotype }\end{array}$ & Taxon & coef & pval & qval & $\begin{array}{c}\text { IQR } \\
\text { Wi_APCMin }\end{array}$ & IQR Wi & $\begin{array}{c}\text { IQR } \\
\text { APCMin }\end{array}$ & IQR WT \\
\hline \multirow{4}{*}{ Phylum } & \multirow[b]{2}{*}{ Wi_APCMin } & Deferribacteres & - & 0.0003 & 0.0031 & $0.06-0.13$ & $0.01-0.13$ & $1.94-4.34$ & $2.67-3.81$ \\
\hline & & Proteobacteria & - & 0.0022 & 0.0123 & $5.3-7.34$ & $2.58-6.69$ & $16.73-19.03$ & $9.84-13.72$ \\
\hline & \multirow{2}{*}{ Winnie } & Deferribacteres & - & 0.0002 & 0.0031 & $0.06-0.13$ & $0.01-0.13$ & $1.94-4.34$ & $2.67-3.81$ \\
\hline & & Proteobacteria & - & 0.0006 & 0.0037 & $5.3-7.34$ & $2.58-6.69$ & $16.73-19.03$ & $9.84-13.72$ \\
\hline \multirow{16}{*}{ Family } & \multirow{11}{*}{ Wi_APCMin } & Acholeplasmataceae & + & 0.0002 & 0.0034 & $0.37-1.12$ & $0.36-0.57$ & $0-0.01$ & $0.01-0.04$ \\
\hline & & Bacteroidaceae & + & 0.0045 & 0.0187 & $8.13-15.14$ & $3.35-5.61$ & $1.26-4.49$ & $1.01-3.56$ \\
\hline & & Clostridiaceae_1 & - & 0.0006 & 0.0045 & $0.11-0.22$ & $0.35-0.58$ & $0.51-1.83$ & $0.24-0.46$ \\
\hline & & Clostridiaceae_2 & + & 0.0027 & 0.0134 & $0.93-2.08$ & $1.63-3.35$ & $0.18-0.24$ & $0.27-0.89$ \\
\hline & & Coriobacteriaceae & - & 0.0028 & 0.0134 & $0.06-0.12$ & $0.37-0.73$ & $0.25-0.45$ & $0.12-0.16$ \\
\hline & & Deferribacteraceae & - & 0.0003 & 0.0034 & $0.06-0.13$ & $0.01-0.13$ & $2.08-4.57$ & $2.83-3.98$ \\
\hline & & Eubacteriaceae & + & $<0.0001$ & 0.0031 & $0.61-1.16$ & $2.48-4.23$ & $0.03-0.07$ & $0.08-0.09$ \\
\hline & & Helicobacteraceae & - & 0.0053 & 0.0205 & $0.92-2.89$ & $0.43-2.47$ & 9.17-15.1 & $5.31-9.97$ \\
\hline & & Lactobacillaceae & - & 0.0002 & 0.0034 & $0.28-0.56$ & $0.87-1.47$ & $1.46-4.42$ & $1.46-2.04$ \\
\hline & & Prevotellaceae & + & 0.0017 & 0.0100 & $12.95-20.68$ & $9.23-12.92$ & $1.02-6.65$ & $1.99-4.92$ \\
\hline & & Verrucomicrobiaceae & + & 0.0008 & 0.0054 & $3.17-7.15$ & $0.49-3.11$ & $0.07-0.21$ & $0.01-0.36$ \\
\hline & \multirow{5}{*}{ Winnie } & Clostridiaceae_2 & + & 0.0005 & 0.0043 & $0.93-2.08$ & $1.63-3.35$ & $0.18-0.24$ & $0.27-0.89$ \\
\hline & & Deferribacteraceae & - & 0.0003 & 0.0034 & $0.06-0.13$ & $0.01-0.13$ & $2.08-4.57$ & $2.83-3.98$ \\
\hline & & Enterobacteriaceae & - & 0.0039 & 0.0170 & $0.02-0.17$ & $0.01-0.01$ & $0.09-0.49$ & $0.01-0.04$ \\
\hline & & Eubacteriaceae & + & $<0.0001$ & 0.0003 & $0.61-1.16$ & $2.48-4.23$ & $0.03-0.07$ & $0.08-0.09$ \\
\hline & & Helicobacteraceae & - & 0.0018 & 0.0100 & $0.92-2.89$ & $0.43-2.47$ & $9.17-15.1$ & $5.31-9.97$ \\
\hline \multirow{7}{*}{ Genus } & \multirow{7}{*}{ Wi_APCMin } & Acholeplasma & + & 0.0002 & 0.0037 & 0.39-1.19 & $0.38-0.58$ & $0-0.01$ & $0.01-0.04$ \\
\hline & & Akkermansia & + & 0.0007 & 0.0066 & $3.36-7.52$ & $0.52-3.29$ & $0.06-0.22$ & $0.01-0.38$ \\
\hline & & Alkaliphilus & + & 0.0016 & 0.0124 & $0.97-2.18$ & $1.71-3.33$ & $0.1-0.23$ & $0.25-0.89$ \\
\hline & & Alloprevotella & + & $<0.0001$ & $<0.0001$ & $1.59-2.55$ & $0.98-2.52$ & $0.01-0.1$ & $0-0.01$ \\
\hline & & Bacteroides & + & 0.0045 & 0.0267 & $8.63-15.00$ & $3.52-6.01$ & $1.33-4.66$ & $1.07-3.79$ \\
\hline & & $\begin{array}{l}\text { Clostridium sensu } \\
\text { stricto }\end{array}$ & - & 0.0007 & 0.0066 & $0.11-0.21$ & $0.34-0.54$ & $0.51-1.85$ & $0.23-0.48$ \\
\hline & & Eubacterium & + & $<0.0001$ & 0.0008 & $0.62-1.18$ & $2.6-4.28$ & $0.03-0.05$ & $0.05-0.07$ \\
\hline
\end{tabular}


Table 1. Cont.

\begin{tabular}{|c|c|c|c|c|c|c|c|c|}
\hline $\begin{array}{c}\text { Mice } \\
\text { Genotype }\end{array}$ & Taxon & coef & pval & qval & $\begin{array}{c}\text { IQR } \\
\text { Wi_APCMin }\end{array}$ & IQR Wi & $\begin{array}{c}\text { IQR } \\
\text { APCMin }\end{array}$ & IQR WT \\
\hline & Helicobacter & - & 0.0059 & 0.0323 & $0.98-3.05$ & $0.41-2.62$ & $9.41-15.65$ & $5.67-10.43$ \\
\hline & Lactobacillus & - & 0.0002 & 0.0037 & $0.3-0.59$ & $0.92-1.51$ & $1.47-4.62$ & $1.55-2.12$ \\
\hline & Odoribacter & - & 0.0023 & 0.0155 & $0.99-1.42$ & $0.71-1.6$ & $2.22-4.5$ & $3.26-3.65$ \\
\hline & Paraprevotella & + & $<0.0001$ & 0.0012 & $0.80-2.87$ & $1.07-2.15$ & $0.01-0.06$ & $0.02-0.09$ \\
\hline & Porphyromonas & + & 0.0021 & 0.0150 & $0.41-0.64$ & $0.39-0.92$ & $0.09-0.2$ & $0.05-0.09$ \\
\hline & Prevotella & + & 0.0038 & 0.0242 & $9.11-15.07$ & $6.07-8.24$ & $0.62-6.54$ & $1.96-5$ \\
\hline & Stomatobaculum & - & 0.0009 & 0.0077 & $0.08-0.15$ & $0.18-0.57$ & $1.28-3.33$ & $2.18-5.3$ \\
\hline & Syntrophococcus & - & 0.0080 & 0.0418 & $0.01-0.06$ & $0.02-0.05$ & $0.2-0.59$ & $0.13-0.69$ \\
\hline & Ureaplasma & - & 0.0006 & 0.0066 & $0-0.04$ & $0.01-0.06$ & $0.28-0.57$ & $0.14-0.25$ \\
\hline \multirow{9}{*}{ Winnie } & Acholeplasma & + & 0.0005 & 0.0053 & $0.39-1.19$ & $0.38-0.58$ & $0-0.01$ & $0.01-0.04$ \\
\hline & Alkaliphilus & + & 0.0003 & 0.0038 & $0.97-2.18$ & $1.71-3.33$ & $0.1-0.23$ & $0.25-0.89$ \\
\hline & Alloprevotella & + & $<0.0001$ & 0.0003 & $1.59-2.55$ & $0.98-2.52$ & $0.01-0.1$ & 0-0.01 \\
\hline & Escherichia/Shigella & - & 0.0082 & 0.0418 & $0.01-0.17$ & n.d.* & $0.09-0.49$ & $0.01-0.04$ \\
\hline & Eubacterium & + & $<0.0001$ & 0.0001 & $0.62-1.18$ & $2.6-4.28$ & $0.03-0.05$ & $0.05-0.07$ \\
\hline & Odoribacter & - & 0.0052 & 0.0293 & $0.99-1.42$ & $0.71-1.6$ & $2.22-4.5$ & $3.26-3.65$ \\
\hline & Paraprevotella & + & 0.0002 & 0.0037 & $0.80-2.87$ & $1.07-2.15$ & $0.01-0.06$ & $0.02-0.09$ \\
\hline & Porphyromonas & + & 0.0014 & 0.0115 & $0.41-0.64$ & $0.39-0.92$ & $0.09-0.2$ & $0.05-0.09$ \\
\hline & Ureaplasma & - & 0.0040 & 0.0242 & 0-0.04 & $0.01-0.06$ & $0.28-0.57$ & $0.14-0.25$ \\
\hline
\end{tabular}

* n.d.: not detected. 


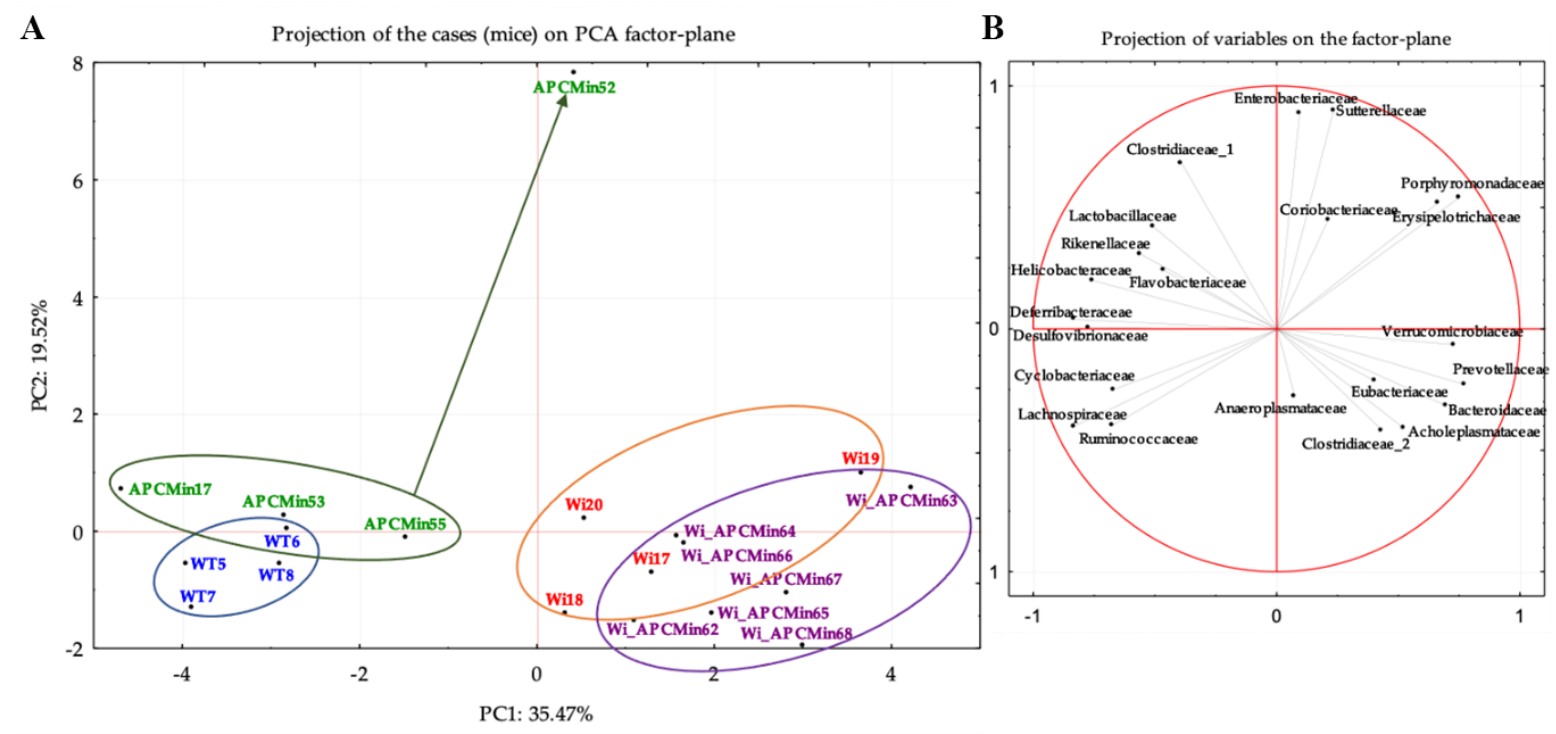

Figure 2. Principal component analysis (PCA). The left panel (A) shows $\beta$-diversity at the family level (16S rDNA gene amplicon) in 8-week-old Winnie-APC Min/+ (Wi_APCMin), Winnie (Wi), APC ${ }^{\text {Min/+ }}$ (APCMin), and C57BL/6J mice (WT). The right panel (B) shows variables weight on PCA system based on normalized bacterial family abundances. Variables placed in both the right quadrants of the PCA system show positive standardized values of the first principal component (PC1). Variables showing negative standardized PC1 values were placed into the two left quadrants. Variables placed in both the upper quadrants of the PCA system show positive standardized values of the second principal component (PC2). Variables showing negative standardized PC2 values were placed into the two lower quadrants.

In order to identify genus clusters characterizing gut microbiota of Winnie-APC Min/+, Winnie, $\mathrm{APC}^{\mathrm{Min} /+}$, and C57BL/6J (WT) mice, we performed a permutation analysis (Figure 3). Based on the clustering of bacterial genera into three clusters (A, B, and C), mice were clustered in two different clusters (1 and 2). One $\mathrm{APC}^{\mathrm{Min} /+}$ sample (APC $\left.{ }^{\mathrm{Min}} 52\right)$ was purged out as outlier based on genera included into cluster " $\mathrm{C}$ ". Therefore, the cluster 1 included only Winnie-APC Min/+ and Winnie mice, which showed high scores of genera belonged to cluster " $\mathrm{A}$ " and negative scores of genera belonged to cluster " $\mathrm{B}$ ". Conversely, cluster 2 included the other three APCMin/+ samples and all the four WT mice. This resulted by the high abundances of genera included into cluster " $\mathrm{B}$ " (in particular the subcluster "B2"), related to negative scores of genera included into cluster "A".

As reported in Table 1 and Figure S3, both Winnie-APC ${ }^{\text {Min/+ }}$ and Winnie mice showed a significantly positive association $(p \leq 0.001 ; q<0.02)$ with Acholeplasma, Alkaliphilus, Alloprevotella, Eubacterium, Paraprevotella, and Porphyromonas (all included in the cluster "A", except Eubacterium). Additionally, both shared the negative association with Helicobacter, Odoribacter, Mucispirillum, and Ureaplasma abundances ( $p \leq 0.006 ; q \leq 0.032)$, included into subcluster "B2", except Ureaplasma. Meanwhile, only Winnie-APC ${ }^{\mathrm{Min} /+}$ reported a positive association with Akkermansia, Bacteroides, and Prevotella $(p \leq 0.005 ; q \leq 0.027)$ and negative with Clostridium sensu stricto, lactobacilli, Rikenella, Stomatobaculum and Syntrophococcus abundances ( $p \leq 0.008 ; q \leq 0.042)$. Differently, only Winnie mice reported a positive association with Porphyromonas $(p=0.001 ; q=0.012)$ and negative with the Escherichia/Shigella pattern $(p=0.008 ; q=0.042)$. 


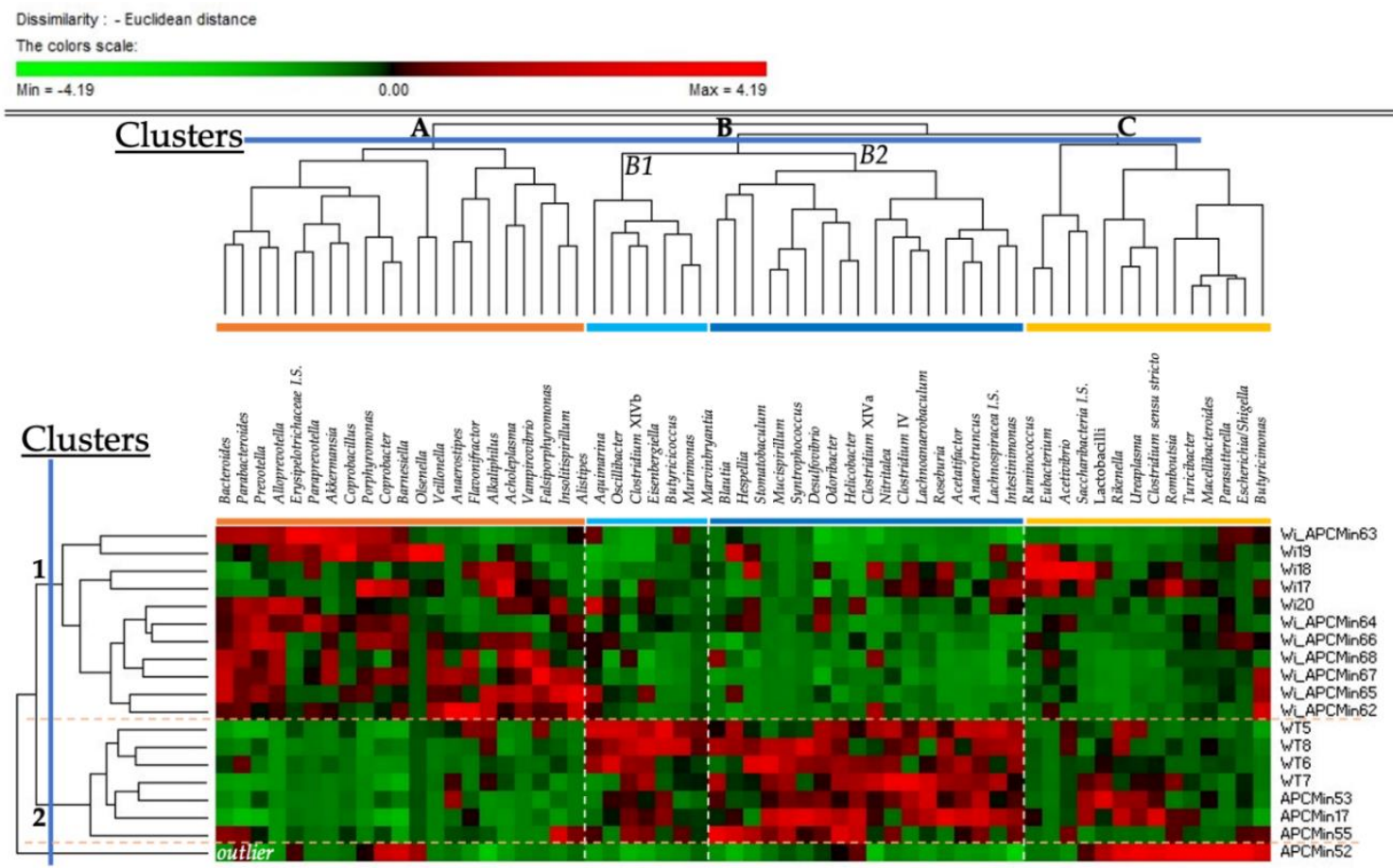

Figure 3. Permutation analysis of bacterial genera with a relative abundance ( $16 \mathrm{~S}$ rDNA gene amplicon) $>0.5 \%$ in at least one 8-week-old Winnie-APC ${ }^{\text {Min/+ }}$ (Wi_APCMin), Winnie (Wi), APC ${ }^{\text {Min/+ }}$ (APCMin), or C57BL/6J (WT) mouse.

Based on obtained results, we noted that all significant associations ( $p$ - and $q$-values $<0.05$ ) were related to Winnie and/or Winnie-APC $\mathrm{Min} /+$ mice. Thus, in order to ascertain which OTUs mainly characterized microbiota of Winnie and/or Winnie-APC ${ }^{\mathrm{Min} /+}$, we performed a statistical analysis also at the species level, investigating OTUs with a mean value of relative abundance $>1 \%$. As reported in Table 2, we found 10 OTUs that significantly colonized the microbiota of Winnie, Winnie-APC ${ }^{\mathrm{Min} /+}$ mice, or both. A total of 5 out of these 10 OTUs showed the same trend in both Winnie and Winnie-APC ${ }^{\mathrm{Min} /+}$ mice. In detail, Eubacterium coprostanoligenes, Paraprevotella clara, and Prevotellamassilia timonensis were positively associated $(p<0.000 ; q \leq 0.014)$, whereas Lactobacillus intestinalis and $\mathrm{Mu}$ cispirillum schaedleri were negatively associated ( $p<0.000 ; q \leq 0.014$; Table 2$)$. Ruminococcus champanellensis was found positively associated only to Winnie mice $(p=0.001 ; q=0.034)$. In Winnie-APCMin/+ mice, Akkermansia muciniphila and Prevotella oralis were positively associated ( $p \leq 0.001 ; q \leq 0.03)$, whereas Clostridium leptum and Rikenella microfusus were negatively associated $(p<0.001 ; q \leq 0.036)$.

Table 2. Positive (coef + ) or negative (coef -) significant associations ( $p$-value $<0.05$ and $q$-value $<0.05$ ) of bacterial species with a mean abundance $>1 \%$ (16rDNA gene amplicon) among all 8-week-old sampled mice: Winnie-APC $\mathrm{Min/+}$ and Winnie compared to APC ${ }^{\mathrm{Min} /+}$, and C57BL/6J (WT) $(n=4-7$ animals/group).

\begin{tabular}{|c|c|c|c|c|}
\hline OTU & Group & coef & pval & qval \\
\hline Akkermansia muciniphila & $\begin{array}{l}\text { Winnie- } \\
\text { APC }^{\text {Min/+ }}\end{array}$ & + & 0.0007 & 0.0303 \\
\hline $\begin{array}{l}\text { Clostridium leptum } \\
\text { (Clostridium cluster IV) }\end{array}$ & $\begin{array}{l}\text { Winnie- } \\
\text { APC }^{\text {Min/+ }}\end{array}$ & - & 0.0015 & 0.0455 \\
\hline Eubacterium coprostanoligenes & $\begin{array}{l}\text { Winnie- } \\
\mathrm{APC}^{\mathrm{Min} /+}\end{array}$ & + & $<0.0001$ & 0.0007 \\
\hline Lactobacillus intestinalis & $\begin{array}{l}\text { Winnie- } \\
\text { APC }^{\text {Min/+ }}\end{array}$ & - & $<0.0001$ & 0.0079 \\
\hline
\end{tabular}


Table 2. Cont.

\begin{tabular}{|c|c|c|c|c|}
\hline OTU & Group & coef & pval & qval \\
\hline Mucispirillum schaedleri & $\begin{array}{c}\text { Winnie- } \\
\text { APC }\end{array}$ & - & 0.0003 & 0.0142 \\
\hline Paraprevotella clara & $\begin{array}{c}\text { Winnie- } \\
\text { APC }^{\text {Min/+ }}\end{array}$ & + & $<0.0001$ & 0.0043 \\
\hline Prevotella oralis & $\begin{array}{c}\text { Winnie- } \\
\text { APC }^{\text {Min/+ }}\end{array}$ & + & $<0.0001$ & 0.0043 \\
\hline Prevotellamassilia timonensis & $\begin{array}{c}\text { Winnie- } \\
\text { APC }^{\text {Min/+ }}\end{array}$ & + & $<0.0001$ & 0.0006 \\
\hline Rikenella microfusus & $\begin{array}{c}\text { Winnie- } \\
\text { APC }^{\text {Min/+ }}\end{array}$ & - & 0.0002 & 0.0116 \\
\hline Eubacterium coprostanoligenes & Winnie & + & $<0.0001$ & 0.0004 \\
\hline Lactobacillus intestinalis & Winnie & - & 0.0002 & 0.0120 \\
\hline Mucispirillum schaedleri & Winnie & - & 0.0002 & 0.0122 \\
\hline Paraprevotella clara & Winnie & + & 0.0003 & 0.0142 \\
\hline Prevotellamassilia timonensis & Winnie & + & $<0.0001$ & 0.0033 \\
\hline Ruminococcus champanellensis & Winnie & + & 0.0010 & 0.0336 \\
\hline
\end{tabular}

\subsection{The Genetics of Breeding Couple Shapes $A P C^{\text {Min/+ }}$ Mice Intestinal Microbiota}

Even if $\mathrm{APC}^{\mathrm{Min} /+}$ mice mainly developed small intestinal tumors and had a low rate of tumor incidence in the large intestine (as also demonstrated for mice housed in our animal facility) $[43,44]$, we noticed an increased incidence of ACF in the distal colon of $\mathrm{APC}^{\mathrm{Min} /+}$ mice born from heterozygous breeders for the Winnie mutation [40]. Thus, we decided to investigate the role of breeding couple genetics in ACF development. We firstly performed a histological analysis on the large intestine of 8-week-old $\mathrm{APC}^{\mathrm{Min} /+}$ mice born from WT female and APC ${ }^{\text {Min/+ }}$ male breeders. Table 3 shows the absence of dysplastic $\mathrm{ACF}$ incidence in the distal colon of $\mathrm{APC}^{\mathrm{Min} /+}$ mice born from WT breeders as compared to those born from heterozygous breeders for the Winnie mutation [40]. However, occasional non dysplastic and dysplastic ACF in the form of unicryptic lesions and microadenoma $>5$ crypts low-grade (LG) were detected in the medial colon of $\mathrm{APC}^{\mathrm{Min} /+}$ mice born from WT breeders (Table 3).

Then, we investigated if the increase in dysplastic ACF incidence in APC ${ }^{\mathrm{Min} /+}$ mice born from heterozygous breeders for Winnie mutation could be triggered by a "dysbiotic state" of the breeders. In fact, as we recently demonstrated, an intestinal dysbiosis has been observed in the offspring of heterozygous breeders for Winnie mutation [42]. Thus, in order to evaluate how maternal genotype and the relative gut microbiota could impact the gut microbial composition and the development of ACF in APC ${ }^{\mathrm{Min} /+}$ mice, feces of $\mathrm{APC}^{\mathrm{Min} /+}$ mice born from Winnie ${ }^{+/-}(n=4)$ or WT $(n=2)$ mothers was collected at 4 and 8 weeks after birth. With the aim to identify bacterial taxa colonizing gut microbiota of the above reported $\mathrm{APC}^{\mathrm{Min} /+}$ mice, we performed a clustering analysis using as variables bacterial genera with a relative abundance ( $16 \mathrm{~S}$ rDNA gene amplicon) $>1 \%$ at least in one fecal sample. The permutation analysis (Figure 4) showed as both sampled time (4 and 8 week after birth) of $\mathrm{APC}^{\mathrm{Min} /+}$ mice born from WT mothers clustered together. Moreover, only one $\mathrm{APC}^{\mathrm{Min} /+}$ mouse born from Winnie ${ }^{+/-}$was included in this cluster; all the other $\mathrm{APC}^{\mathrm{Min} /+}$ mice born from Winnie ${ }^{+/-}$clustered apart. The main differences between these two clusters were related to three bacterial clusters (I, II, and III; Figure 4). In detail, the bacterial cluster I, including Helicobacter and taxa belonging to the Clostridium cluster XIVa, mainly characterized APC ${ }^{\mathrm{Min} /+}$ mice with WT parental backgrounds. The same was found also concerning the subcluster IIIa, which included Prevotella, Lactobacillus, and Eisenbergiella. On the other side, the cluster II, which included Bacteroides and Odoribacter, was mainly related to $\mathrm{APC}^{\mathrm{Min} /+}$ mice born from Winnie ${ }^{+/-}$mothers. Of note, within the subcluster IIIb, which included bacterial genera not absolutely correlated to one mouse cluster, Parabacteroides and Akkermansia seem to show a trend towards the relationship with $\mathrm{APC}^{\mathrm{Min} /+}$ mice born from Winnie ${ }^{+/-}$mothers. 


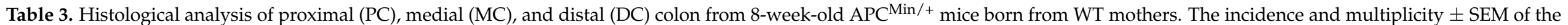

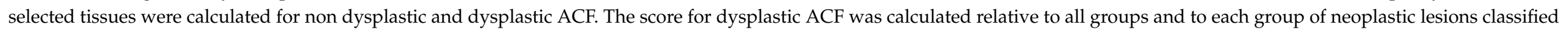

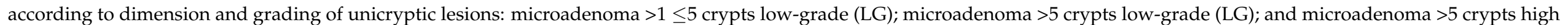
grade (HG).

\begin{tabular}{|c|c|c|c|c|c|c|c|c|c|c|c|c|}
\hline \multirow{3}{*}{$\begin{array}{c}\text { Genotype-Tissue } \\
\text { (n. Mice) }\end{array}$} & \multicolumn{2}{|c|}{ Non Dysplastic ACF } & \multicolumn{10}{|c|}{ Dysplastic ACF } \\
\hline & \multirow[b]{2}{*}{$\begin{array}{c}\text { Incidence } \\
(\%)\end{array}$} & \multirow[b]{2}{*}{$\begin{array}{c}\text { Multiplicity } \\
\text { (Mean } \pm \\
\text { SEM) }\end{array}$} & \multicolumn{2}{|c|}{ All Groups } & \multicolumn{2}{|c|}{ Unicryptic Lesion } & \multicolumn{2}{|c|}{$\begin{array}{c}\text { Microadenoma } \\
<5 \text {-LG }\end{array}$} & \multicolumn{2}{|c|}{ Microadenoma $>5-L G$} & \multicolumn{2}{|c|}{ Microadenoma $>5-\mathrm{HG}$} \\
\hline & & & $\begin{array}{c}\text { Incidence } \\
(\%)\end{array}$ & $\begin{array}{c}\text { Multiplicity } \\
\text { (Mean } \pm \\
\text { SEM) }\end{array}$ & $\begin{array}{l}\text { Incidence } \\
(\%)\end{array}$ & $\begin{array}{c}\text { Multiplicity } \\
\text { (Mean } \pm \\
\text { SEM) }\end{array}$ & $\begin{array}{c}\text { Incidence } \\
(\%)\end{array}$ & $\begin{array}{l}\text { Multiplicity } \\
\text { (Mean } \pm \\
\text { SEM) }\end{array}$ & $\begin{array}{c}\text { Incidence } \\
(\%)\end{array}$ & $\begin{array}{c}\text { Multiplicity } \\
\text { (Mean } \pm \\
\text { SEM) }\end{array}$ & $\begin{array}{c}\text { Incidence } \\
(\%)\end{array}$ & $\begin{array}{c}\text { Multiplicity } \\
\text { (Mean } \pm \\
\text { SEM) }\end{array}$ \\
\hline $\mathrm{APC}^{\mathrm{Min} /+}$-PC (2) & 0 & 0 & 0 & 0 & 0 & 0 & 0 & 0 & 0 & 0 & 0 & 0 \\
\hline $\mathrm{APC}^{\mathrm{Min} /+}-\mathrm{MC}(2)$ & 50 & $0.5 \pm 0.5$ & 100 & $1.5 \pm 0.5$ & 50 & $0.5 \pm 0.5$ & 0 & 0 & 100 & $1.0 \pm 0$ & 0 & 0 \\
\hline $\mathrm{APC}^{\mathrm{Min} /+}-\mathrm{DC}(2)$ & 0 & 0 & 0 & 0 & 0 & 0 & 0 & 0 & 0 & 0 & 0 & 0 \\
\hline
\end{tabular}




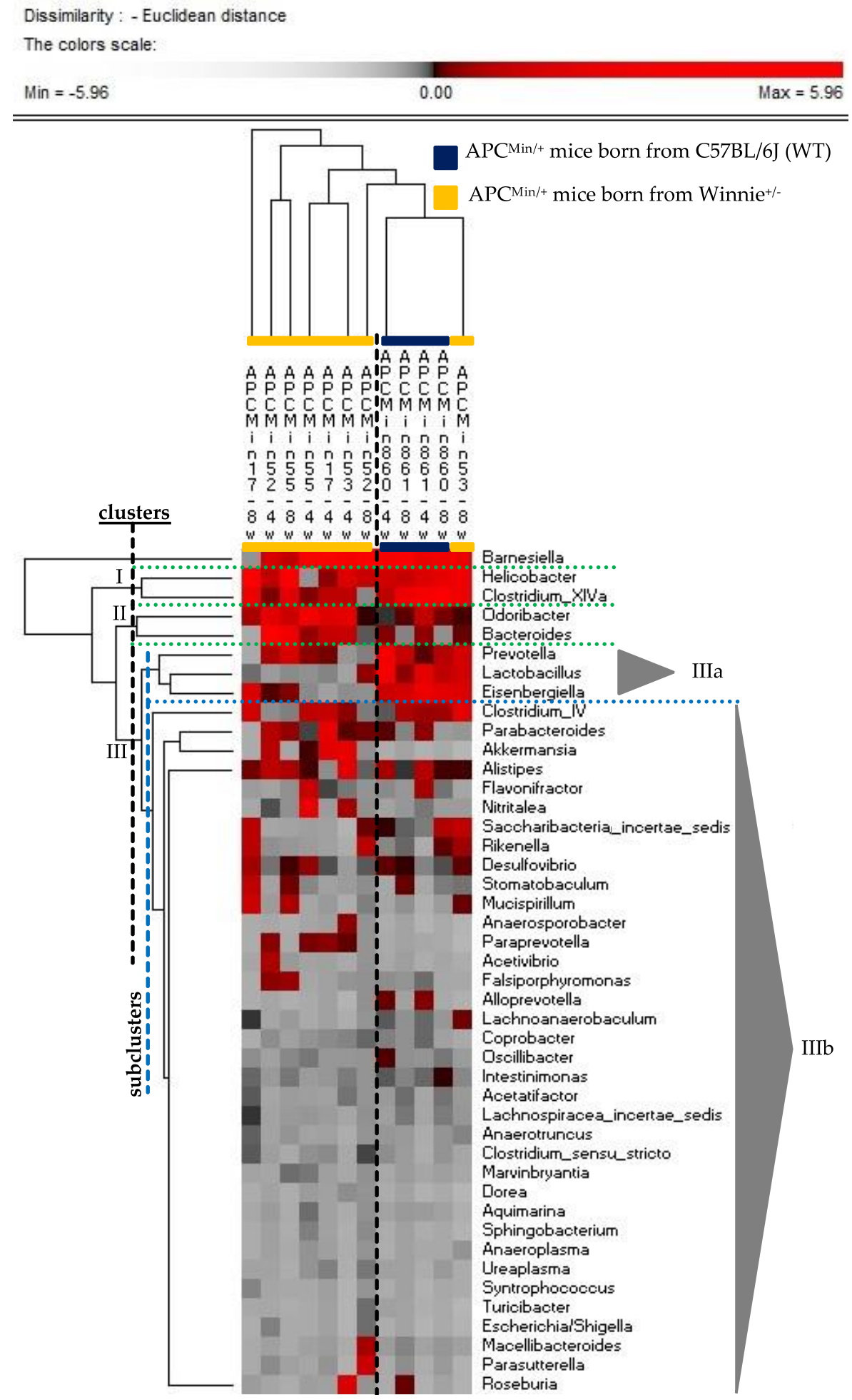

Figure 4. Permutation analysis of bacterial genera with a relative abundance (16S rDNA gene amplicon) $>1 \%$ in at least one $\mathrm{APC}^{\mathrm{Min} /+}$ mouse. Feces was sampled from $\mathrm{APC}^{\mathrm{Min} /+}$ born from Winnie $^{+/-}(n=4$; yellow) or C57BL/6J (WT; $n=2$; blue) mice at 4 and 8 weeks after birth.

\subsection{Fecal Transplant from Winnie to APC ${ }^{\mathrm{Min} /+}$ Mice Triggers ACF Development}

To test the hypothesis of dysbiotic microbiota as a transmittable factor for ACF development, we performed a fecal transplant from Winnie donors into $\mathrm{APC}^{\mathrm{Min} /+}$ mice born from WT mothers. APC ${ }^{\mathrm{Min} /+}$ mice were treated with broad spectrum antibiotics for two 
weeks and gavaged with a suspension of fecal material from WT or Winnie donors for the following two weeks. At the end of the experiment, mice were sacrificed, and the colon explanted and histologically analyzed to evaluate ACF development (Figure 5).

A

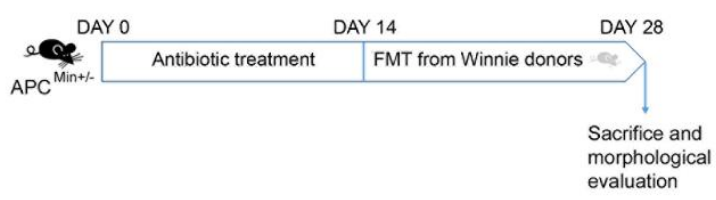

B
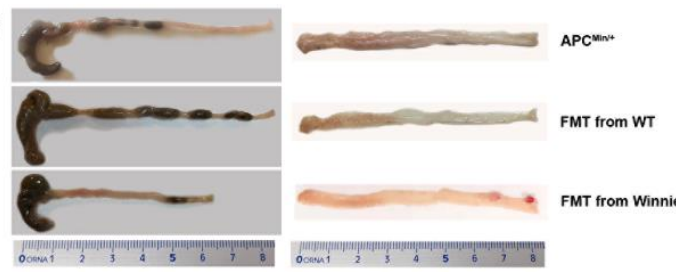

D

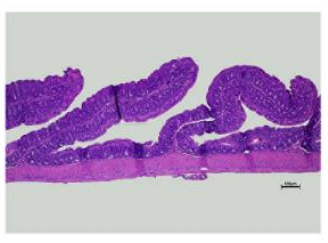

$\mathbf{E}$

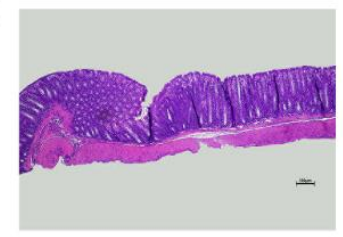

C

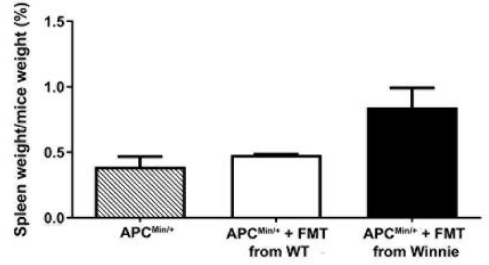

F

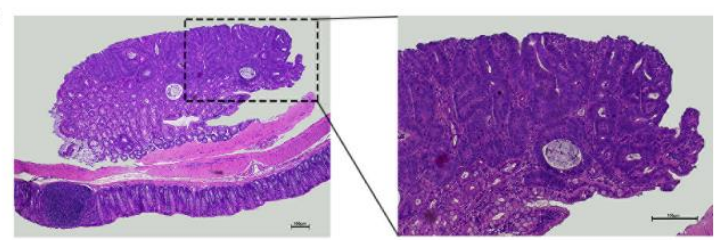

Figure 5. Fecal microbiota transplantation (FMT) from WT or Winnie donors in APC Min/+ mice born from WT mothers. (A) Experimental scheme of FMT protocol. (B) Representative image of colon explanted from untreated APC ${ }^{\mathrm{Min} /+}$ and $\mathrm{APC}^{\mathrm{Min} /+}$ mice after FMT treatment. (C) Ratio of spleen weight vs. mice weight was calculated for the three experimental groups. (D-F) Representative H\&E staining on colon sections from proximal (D), medial (E), and distal (F) tract of APCMin/+ mice with FMT from Winnie mice. Images were captured at 10X and 20X magnifications. Scale bar $=100 \mu \mathrm{M}$.

Compared to untreated $\mathrm{APC}^{\mathrm{Min} /+}$ mice, fecal transplant of Winnie microbiota induced the formation of large tumor lesions in the distal colon leading to partial intestinal obstruction (Figure 5B, right panel and F), and a tendency to splenomegaly (Figure 5C). Colons from $\mathrm{APC}^{\mathrm{Min} /+}$ mice after fecal transplant from Winnie also showed watery stool, as compared to control groups (Figure $5 \mathrm{~B}$, left panel). Table 4 showed the highest incidence of dysplastic $\mathrm{ACF}$, ranging from unicryptic lesion to microadenoma $>5 \mathrm{HG}$, in the distal colon of $\mathrm{APC} \mathrm{Min} /+$ mice after fecal transplant from Winnie mice. However, the transplant of fecal homogenate from Winnie mice also induced the onset of non dysplastic ACF as well as dysplastic microadenoma $>1 \leq 5 \mathrm{LG}$ and microadenoma $>5$ LG in the medial colon of $\mathrm{APC}^{\mathrm{Min} /+}$ mice. Moreover, non dysplastic ACF were also seen in the medial colon of $\mathrm{APC}^{\mathrm{Min} /+}$ mice treated with fecal transplant from WT donors, whilst no dysplastic lesions were observed in this experimental group. 


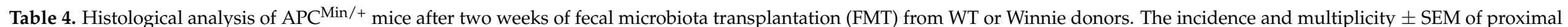

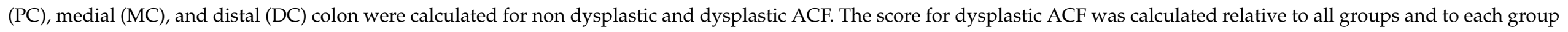

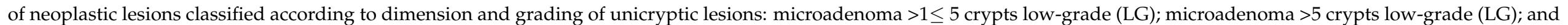
microadenoma $>5$ crypts high grade (HG).

\begin{tabular}{|c|c|c|c|c|c|c|c|c|c|c|c|c|}
\hline \multirow[b]{3}{*}{$\begin{array}{c}\text { Genotype Tissue } \\
\text { Treatment (n. } \\
\text { Mice) }\end{array}$} & \multicolumn{2}{|c|}{ Non Dysplastic ACF } & \multicolumn{10}{|c|}{ Dysplastic ACF } \\
\hline & \multirow[b]{2}{*}{$\begin{array}{l}\text { Incidence } \\
(\%)\end{array}$} & \multirow[b]{2}{*}{$\begin{array}{l}\text { Multiplicity } \\
\text { (Mean } \pm \\
\text { SEM) }\end{array}$} & \multicolumn{2}{|c|}{ All Groups } & \multicolumn{2}{|c|}{ Unicryptic Lesion } & \multicolumn{2}{|c|}{ Microadenoma $>1 \leq 5-$ LG } & \multicolumn{2}{|c|}{ Microadenoma >5-LG } & \multicolumn{2}{|c|}{ Microadenoma $>5-$ HG } \\
\hline & & & $\begin{array}{c}\text { Incidence } \\
(\%)\end{array}$ & $\begin{array}{c}\text { Multiplicity } \\
\text { (Mean } \pm \\
\text { SEM) }\end{array}$ & $\begin{array}{c}\text { Incidence } \\
(\%)\end{array}$ & $\begin{array}{l}\text { Multiplicity } \\
\text { (Mean } \pm \\
\text { SEM) }\end{array}$ & $\begin{array}{c}\text { Incidence } \\
(\%)\end{array}$ & $\begin{array}{c}\text { Multiplicity } \\
\text { (Mean } \pm \text { SEM) }\end{array}$ & $\begin{array}{c}\text { Incidence } \\
(\%)\end{array}$ & $\begin{array}{c}\text { Multiplicity } \\
\text { (Mean } \pm \\
\text { SEM) }\end{array}$ & $\begin{array}{c}\text { Incidence } \\
(\%)\end{array}$ & $\begin{array}{c}\text { Multiplicity } \\
\text { (Mean } \pm \\
\text { SEM) }\end{array}$ \\
\hline $\begin{array}{c}\mathrm{APC}^{\mathrm{Min} /+}+\mathrm{PC} \\
\text { with FMT from } \\
\text { WT (3) }\end{array}$ & 0 & 0 & 0 & 0 & 0 & 0 & 0 & 0 & 0 & 0 & 0 & 0 \\
\hline $\begin{array}{l}\mathrm{APC}^{\mathrm{Min} /+}+\mathrm{PC} \\
\text { with FMT from } \\
\text { Winnie (7) }\end{array}$ & 0 & 0 & 0 & 0 & 0 & 0 & 0 & 0 & 0 & 0 & 0 & 0 \\
\hline $\begin{array}{c}\mathrm{APC}^{\mathrm{Min} /+}+\mathrm{MC} \\
\text { with FMT from } \\
\text { WT (3) }\end{array}$ & 33.3 & $0.33 \pm 0.33$ & 0 & 0 & 0 & 0 & 0 & 0 & 0 & 0 & 0 & 0 \\
\hline $\begin{array}{c}\mathrm{APC}^{\mathrm{Min} /+}-\mathrm{MC} \\
\text { with FMT from } \\
\text { Winnie (7) }\end{array}$ & 14.3 & $0.14 \pm 0.14$ & 42.6 & $0.43 \pm 0.2$ & 0 & 0 & 28.6 & $0.29 \pm 0.19$ & 14.3 & $0.14 \pm 0.14$ & 0 & 0 \\
\hline $\begin{array}{c}\mathrm{APC}^{\mathrm{Min} /+}-\mathrm{DC} \\
\text { with FMT from } \\
\text { WT (3) }\end{array}$ & 0 & 0 & 0 & 0 & 0 & 0 & 0 & 0 & 0 & 0 & 0 & 0 \\
\hline $\begin{array}{l}\mathrm{APC}^{\mathrm{Min} /+}+\mathrm{DC} \\
\text { with FMT from } \\
\text { Winnie (7) }\end{array}$ & 14.3 & $0.86 \pm 0.86$ & 42.6 & $0.86 \pm 0.6$ & 14.3 & $0.14 \pm 0.14$ & 14.3 & $0.14 \pm 0.14$ & 28.6 & $0.14 \pm 0.37$ & 28.6 & $0.29 \pm 0.19$ \\
\hline
\end{tabular}




\section{Discussion}

Numerous reports highlight the link between intestinal microbiota and CRC [45]. Based on our results, the Winnie-APC Min/+ model is characterized by an intestinal microbial composition that mainly resembles characteristics of the parental strain Winnie. This was particularly shown by the $\beta$-diversity analysis, where we observed the clear microbial proximity between Winnie and Winnie-APC ${ }^{\mathrm{Min} /+}$. This finding also supports what we previously observed in terms of body weight for Winnie-APC ${ }^{\mathrm{Min} /+}$ and Winnie mice [42].

Our breeding strategy relies on heterozygote mothers for Muc2 point mutation (Winnie $^{+/-}$mice) characterized by a mild dysbiosis transmittable to the offspring and the acquisition of distinct characteristics dictated their own genetics at 8 weeks. One of the main features characterizing Winnie mice is the increased abundance of Akkermansia muciniphila [42]. Additionally, Winnie mice have a less-tight mucus layer providing an easier access to mucin metabolized by mucin degrader bacteria, such as A. muciniphila, as a source of energy [46]. Of note, in the present work Akkermansia was associated with Winnie-APC Min/+ even more significantly than Winnie mice. This might be interesting, considering that in dextran sodium sulfate (DSS)-induced colitis, Akkermansia showed the capability to produce extracellular vesicles protecting the host from colitis progression [47]. However, we want to emphasize that further studies are needed to deeply understand how Akkermansia contributes (protecting or promoting) to a specific subset of pathologies, particularly in chronic intestinal inflammations and related ones.

Apart from Akkermansia, data obtained from gut microbiota sequencing (16S rDNA gene amplicon) indicated that Winnie-APC $\mathrm{Min} /+$ mice harbor a bacterial pattern mainly characterized by Bacteroidaceae, Prevotellaceae, Acholeplasmataceae, Eubacteriaceae, and clostridia not belonging to Clostridium sensu stricto. Conversely, a low abundance of butyrogenic bacteria was found, specifically Bifidobacteriaceae, Lactobacillaceae, Lachnospiraceae, Ruminococcaceae, and the relative subtaxa. These findings were shared with Winnie mice, whereas APC $\mathrm{Min} /+$ and C57BL/6J showed exactly the opposite. The increase in Bacteroides and Prevotella abundances in Winnie-APC ${ }^{\mathrm{Min} /+}$ compared to WT mice strengthens the power of this model in resembling the human pathology, considering the evidence found in CRC patients when compared to healthy controls [48]. Moreover, gut microbiota sequencing of Winnie-APC Min/+ mice confirmed an early important feature of the intestinal dysbiosis leading to CRC in humans, i.e., the decrease in Firmicutes to Bacteroidetes ratio relative to WT mice, in accordance with data found in subjects with preneoplastic/neoplastic lesions [49]. Under another point of view, Bacteroides have been previously correlated with a low hypermethylation of several gene promoters, including Wif1 (Wnt Inhibitory Factor 1) for the Wnt pathway and Neuropeptide Y (NPY) and Proenkephalin (PENK) for the brain gut system, as recently demonstrated in a large cohort of patients [50]. In the same work, the aforementioned butyrogenic bacteria were associated with a higher cumulative methylation index (CMI) indicating gene expression silencing, by gene methylation, relative to the host genes involved in CRC pathways [50]. Taking into account these recent findings and, in general, the role of epigenetics in CRC onset and progression [51,52], it is tempting to speculate that the dysbiosis of Winnie-APC $\mathrm{Min} /+$ mice also supported ACF development via an epigenome dysregulation.

The protective role of SCFA-producing bacteria is widely recognized [53,54]. Among SCFAs, butyrate exerts a beneficial effect on intestinal inflammation due to its effect on tight junctions in maintaining the integrity of the epithelial barrier $[55,56]$ and therefore favoring mucus excretion by enterocytes. Even if the protective role of butyrate-producing bacteria could be controversial in some cases [57], in our study the beneficial role also emerges by comparing the microbial profiling of APC ${ }^{\mathrm{Min} /+}$ mice born from WT or Winnie ${ }^{+/-}$breeders. In this line, maternal dysbiosis in Winnie mice could be considered as a trigger acting on the genetic background of $\mathrm{APC}^{\mathrm{Min} /+}$ mice to promote $\mathrm{ACF}$ development. The loose mucus layer, typical of Winnie mice, increases the intestinal permeability allowing bacteria to invade the mucosa with a consequent activation of the immune response. Thus, all these microenvironmental modulations lay the ground for specific bacteria (e.g., Bacteroides) 
to act as inflammatory and tumorigenic triggers. Different Bacteroides taxa are, indeed, lipopolysaccharide (LPS) producers [58]. Moreover, LPS has been found to induce IL-8 activation in human intestinal epithelial cells and this has been related to specific histone acetylation and methylation changes [59]. Therefore, this evidence, combined with the low grade of SCFA excretion and the derived easy contact of microbial antigens to the intestinal epithelium, may boost inflammatory features as well as the formation of ACF. Moreover, based on the protective role of Mucispirillum schaedleri in different mice diseases [60], the lowest amount of this bacterial strain in Winnie and Winnie-APC ${ }^{\mathrm{Min} /+}$ models may contribute to CAC and thus warrants further investigation. However, due to the lack of genome and transcriptome analyses, we would underline that the pathogenicity is not related only to the presence/absence of pathobiont, more than probiotic, taxa. Meanwhile, we would emphasize that this is the result of a multifactorial interaction, in which the host genotype, combined with the lack of butyrogenic bacteria and the related expansion of other taxa replacing beneficial microbes, drives the onset of CRC.

Even if our data are in line with the dysbiotic pattern supporting CRC pathogenesis, we acknowledge some discrepancies relative to the recent literature. In fact, differently from what has been reported in other studies [61,62], in our experimental setup the Erysipelotrichaceae was not among the most represented family and we even detected a slight increase in the Winnie-APC Min/+ model. These data suggest that variability among the animal facility represents a crucial difference that will require further investigation. On the other hand, different models may lead to different results representing distinct but relevant risk factors for CRC development.

Our current data are still not sufficient to provide the final proof that dysbiosismediated inflammation is the main trigger of CAC development in Winnie-APC $\mathrm{Min} /+^{+}$mice, although timing and location of the ACF represent a strong hint supporting this hypothesis. Furthermore, the observed results should be discussed considering that the ACF with low incidence observed in the APC $\mathrm{Min} /+$ offspring of Winnie ${ }^{+/-}$mothers may be the result of a cascade of events dictated by the presence/absence of specific intestinal taxa that leads to inflammation and tumor lesion development. In fact, in the distal colon of 8-weekold APC ${ }^{\mathrm{Min} /+}$ offspring from WT mothers, ACF are extremely rare [43]. Considering this evidence, it is tempting to speculate that microbiota supports CRC onset and, therefore, may represent a risk factor for transmittable susceptibility to ACF development in genetically predisposed individuals.

We would also support the idea that Winnie-APC ${ }^{\mathrm{Min} /+}$ mice microbiota profiling could help to define adjuvant treatments targeting gut microbiota imbalances. These treatments, combined with common chemotherapy and/or immunotherapy strategies, might ameliorate CRC treatment efficacy. Additionally, probiotics and prebiotics, defined as live microorganisms promoting beneficial effects to the host and indigestible fibers harboring the growth of health-promoting bacteria (respectively), may drive or reduce an overexpansion of undesirable microbes. Both these non-medical therapies could contribute, as adjuvant treatments, to regulating the immune response, macrophage and lymphocyte activation, and the proliferation/differentiation of intestinal epithelial cells [35]. The end goal remains undoubtedly a beneficial influence towards the intestinal barrier function. Furthermore, diet is recognized as one of the most influencing factors able to shape gut microbiota with a health-promoting effect associated with a high intake of food enriched in fiber and bioactive compounds, e.g., polyphenols, characterized by a well-known antiinflammatory effect [63].

Taken together, the data reported in the present study could be useful for the design of appropriate microbiota-based screening and preventive strategies for genetically predisposed individuals in order to avoid CRC onset and/or progression. Together with others, we recently demonstrated that nutritional-based strategies could be effective in bending intestinal microbiota towards an eubiotic state (balanced microbial composition). This possibility should be explored as a preventive/adjuvant strategy [63-65]. Positive results may also help to reduce the huge financial costs for the health system related to 
ever increased number of diagnoses for inflammatory diseases as well as for their related pathological conditions.

It is important to note that our results referred to fecal specimens. Even if the analysis of tissue samples from colonic mucosa seems to be more valuable to study CRC physiopathology, many of the studies on gut microbiota are performed on fecal specimens due to the non-invasive nature of sample collection.

Finally, further studies on microbiota modulation in the Winnie-APC ${ }^{\mathrm{Min} /+}$ model have to be extended to the non-bacterial components of the microbiome (i.e., fungi, protozoans, viruses). In fact, even if the pathogenetic role for CRC of these microorganisms is already known, the knowledge of their mechanisms of action is still underestimated probably due to their lower abundances and/or the technical difficulties in targeting them [35]. Future perspectives for this study will also include the use of complementary approaches, such as metatranscriptomics, metabolomics and metaproteomics, to provide a deeper comprehension of host-microbes interactions. Currently, a multiomics approach is ongoing to evaluate the crosstalk between intestinal resident microbiota and the intestinal epithelium, with a particular interest in the metabolites produced in close proximity to the tumor lesions.

\section{Materials and Methods}

\subsection{Mice}

Animal studies were conducted in accordance with national and international guidelines and were approved by the authors' institutional review board (Organism For Animal Wellbeing-OPBA). All animal experiments were carried out in accordance with Directive 86/609 EEC enforced by Italian D.L. n. 26/2014, and approved by the Italian Animal Ethics Committee of Ministry of Health-General Directorate of Animal Health and Veterinary Drugs (DGSAF- Prot. 768/2015-PR 27/07/2015). Animals were sacrificed if found in severe clinical condition to avoid undue suffering.

The new murine transgenic line Winnie-APC ${ }^{\mathrm{Min} /+}$ was created by breeding Winnie ${ }^{+/-}$ mice with $\mathrm{APC} \mathrm{Min} /+^{+}$mice on a C57BL/6J background. WT and $\mathrm{APC}^{\mathrm{Min} /+}$ mice murine lines were purchased from Jackson Laboratories (C57BL/6J, Stock No. 000664, C57BL/6JAPCMin/J, Stock No. 002020, respectively) (Bar Harbor, ME, USA). Winnie mice were obtained from the University of Tasmania, Launceston, Australia (Dr R. Eri's laboratory). The 4 experimental groups are composed of 4 mice for the C57BL/6J (wild type, WT), Winnie, and $\mathrm{APC}^{\mathrm{Min} /+}$ groups and 7 mice for the Winnie-APC ${ }^{\mathrm{Min} /+}$ group.

Mice were sacrificed at 8 weeks of age; colons were removed to evaluate the presence of neoplasia and metagenetic analyses was performed on stool.

\subsection{Histology}

Tissue sections from the large intestine were fixed in $10 \%$ buffered formalin, dehydrated, and paraffin embedded. Then, $3-\mu \mathrm{m}$-thick sections from proximal, medial, and distal colon were stained using a hematoxylin/eosin standard protocol. Colonic tissue sections were evaluated for neoplasia. Observations and imaging were performed with a Nikon Eclipse Ti2.

\subsection{DNA Extraction from Stool}

Total genomic bacterial DNA was isolated from frozen stool samples of 8-week-old mice using the QIAamp ${ }^{\circledR}$ Fast DNA Stool Mini Kit (QIAGEN, Hilden, Germany), according to the manufacturer's instructions.

\subsection{S rDNA Metagenomic Library Preparation, Sequencing and Analysis}

Next generation sequencing experiments, comprising DNA extraction and primary bioinformatics analysis, were performed by Genomix4life S.R.L. (Baronissi, Salerno, Italy). DNA extractions were performed with Invimag Stool kit (Stratec, Birkenfeld, Germany), using an extraction negative control. Final yield and quality of extracted DNA were determined by using NanoDrop ND-1000 spectrophotometer (Thermo Scientific, Waltham, MA, 
USA) and Qubit Fluorometer 1.0 (Invitrogen Co., Carlsbad, CA, USA). 16S amplification was performed with primers: Forward: 5'-CCTACGGGNGGCWGCAG-3' and Reverse: 5'-GACTACHVGGGTATCTAATCC-3' [66], which target the hypervariable V3 and V4 region of the $16 \mathrm{~S}$ rRNA gene. Each PCR reaction was assembled according to Metagenomic Sequencing Library Preparation (Illumina, San Diego, CA, USA). A negative control is included in the workflow; it consists of all reagents used during sample processing (16S amplification and library preparation) but does not contain a sample, to ensure no contamination. Libraries were quantified used Qubit fluorometer (Invitrogen Co., Carlsbad, CA, USA) and pooled to an equimolar amount of each index-tagged sample to a final concentration of $4 \mathrm{nM}$, including the Phix Control Library. Pooled samples were subject to cluster generation and sequenced on MiSeq platform (Illumina, San Diego, CA, USA) in a $2 \times 300$ paired-end format. The raw sequence files generated (fast files) underwent quality control analysis with FastQC.

The 16S rDNA analysis performs taxonomic classification of $16 \mathrm{~S}$ rRNA targeted amplicon reads. The algorithm is a high-performance implementation of the Ribosomal Database Project (RDP) Classifier described in [67]. Taxonomic databases to perform taxonomic classification, after OTU clustering with a $97 \%$ of coverage ( $3 \%$ of divergence), is RefSeq RDP $16 S$ v3 May 2018 DADA2 32bp.

\subsection{Fecal Transplantation}

$\mathrm{APC}^{\mathrm{Min} /+}$ mice $(n=10)$ were treated with broad spectrum antibiotics in their drinking water, which was replaced daily for 2 weeks. After the antibiotic treatment, mice returned to drink fresh water and were gavaged with $0.2 \mathrm{~mL}$ of supernatant from a fresh fecal homogenate pool of 8-month-old WT or Winnie donor mice (3 or $7 \mathrm{APC}^{\mathrm{Min} /+}$ mice were treated, respectively; $\mathrm{n}$ of donor mice $=4$ for each group). Fecal transplant was performed every 2 days for 2 weeks with a stainless-steel tube without prior sedation of the mice. Mice were sacrificed at the end of the experiment and the colon explanted for histological analysis.

\subsection{Statistical Analysis}

Statistical analysis of fecal transplant experimental data was performed using the Graphpad Prism statistical software release 5.0. All data were expressed as means \pm S.E.M. Statistical significance was evaluated with two-tailed Student's t-test and results were considered statistically significant at $p<0.05$.

For microbiota analysis, data were summarized using descriptive statistics, such as means and standard deviations, median, or interquartile range (IQR), as appropriate, for quantitative variables and relative frequencies for qualitative ones. Multivariable association between $16 \mathrm{~S}$ rDNA gene data abundances at different taxonomic levels occurring in mice microbiota was performed using the MaAsLin2 $\mathrm{R}$ package (https: //huttenhower.sph.harvard.edu/maaslin/). The Firmicutes to Bacteroidetes ratios was analyzed by Kruskal-Wallis test corrected with Dunn's multiple comparisons test with a significance level of $p<0.05$. Meanwhile, unless specifically described, data and group differences were analyzed by paired or unpaired, two-tailed Student's $t$-test. Principal component analysis (PCA) $[68,69]$ was carried out using the statistical software Statistica for Windows (Statistica 6.0 for Windows 1998, StatSoft, Vigonza, Italy) based on weighted Unifrac distances. Samples more similar to each other should appear closer together according to the respective axis reflecting the variation among all samples [70]. This technique is useful for displaying clusters existing within data. The variables (features) reflect the relative bacterial composition in a sample at a particular taxonomic level. In addition, Permut-MatrixEN software was used to identify clusters at the level of the mouse groups and taxa [71]. Statistical analysis of the relative abundances of microbial genera was based on Duncan's multiple range test, with a significance level of $p<0.05$. 


\section{Conclusions}

Our results clearly indicate that microbial components of the intestinal tract represent a sufficient trigger for CRC development in genetically predisposed individuals. The paradigm of CRC as non-communicable disease may change in light of these data, particularly when translated to the mother-child microbial transfer. Cancer prevention may soon include prevention of intestinal dysbiosis and treatment for "healthy microbial pattern" selection. We are just starting to understand the complex microbial-host interaction that is much more than just bacterial species-relative abundance. Our data will contribute to shedding light on the importance of microbiome modulation as a prevention strategy in $\mathrm{CRC}$ and, possibly, numerous other pathologies.

Supplementary Materials: The following are available online at https:/ / www.mdpi.com/2072-669 4/13/2/283/s1, Figure S1: Firmicutes to Bacteroidetes ratios was calculated for 8-week-old Winnie$\mathrm{APC}^{\mathrm{Min} /+}$ (Wi_APCMin), Winnie (Wi), APC ${ }^{\mathrm{Min} /+}$ (APCMin), and C57BL/6J (WT). $\left.{ }^{*}\right) p=0.0181$ (Kruskal-Wallis test corrected with Dunn's multiple comparisons test), Figure S2: Positive (coef+) or negative (coef-) associations of bacterial abundances (16rDNA gene amplicon) at family level and mouse genotypes: Winnie-APC ${ }^{\mathrm{Min} /+}$ (Wi_APCMin), Winnie (Wi), APC ${ }^{\mathrm{Min} /+}$ (APCMin), and C57BL/6J (WT), Figure S3: Positive (coef + ) or negative (coef-) associations of bacterial abundances (16rDNA gene amplicon) at genus level and mouse genotypes: Winnie-APC ${ }^{\mathrm{Min} /+}$ (Wi_APCMin), Winnie (Wi), APC ${ }^{\mathrm{Min} /+}$ (APCMin), and C57BL/6J (WT), Table S1: $\alpha$-diversity indices.

Author Contributions: Conceptualization, M.C., M.D.A., R.E., S.D.S. and M.L.; methodology, S.D.S., M.L., G.V., E.C., S.C.; software, M.V., F.M.C.; validation, R.A., M.L. and S.D.S.; formal analysis, M.V., F.M.C.; resources, M.M., A.L.; data curation, M.V., S.D.S., M.L.; writing—original draft preparation, S.D.S., M.V., M.L.; writing—review and editing, M.C., M.D.A.; funding acquisition, M.D.A., M.M., A.L. All authors have read and agreed to the published version of the manuscript.

Funding: S.D.S. is funded by PON—Ricerca e Innovazione 2014-2020—Progetto AIM1801289attività 3-linea $1, \mathrm{ML}$ is supported by $\mathrm{MiCro}, \mathrm{MC}, \mathrm{EC}, \mathrm{RA}, \mathrm{AL}, \mathrm{SC}, \mathrm{MM}$ are supported by Ricerca Corrente 2019, MV, FMC, MDA, MC are supported by PON “2014-2020 E FSC_C.P. ARS01_01220” -BIOMIS.

Institutional Review Board Statement: The study was conducted according to national and international guidelines and was approved by the authors' institutional review board (Organism For Animal Wellbeing-OPBA). All animal experiments were carried out in accordance with Directive 86/609 EEC enforced by Italian D.L. n. 26/2014, and approved by the Italian Animal Ethics Committee of Ministry of Health-General Directorate of Animal Health and Veterinary Drugs (DGSAF- Prot. 768/2015-PR 27/07/2015).

Informed Consent Statement: Not applicable.

Data Availability Statement: The data presented in this study are available on request from the corresponding author.

Acknowledgments: We are grateful to Genomix4life S.R.L. for their support in the next generation sequencing experiments and primary bioinformatics analysis.

Conflicts of Interest: The authors declare no conflict of interest.

\section{References}

1. Bray, F.; Ferlay, J.; Soerjomataram, I.; Siegel, R.L.; Torre, L.A.; Jemal, A. Global cancer statistics 2018: GLOBOCAN estimates of incidence and mortality worldwide for 36 cancers in 185 countries. CA Cancer J. Clin. 2018, 68, 394-424. [CrossRef]

2. Dekker, E.; Tanis, P.J.; Vleugels, J.L.A.; Kasi, P.M.; Wallace, M.B. Colorectal cancer. Lancet 2019, 394, 1467-1480. [CrossRef]

3. Colotta, F.; Allavena, P.; Sica, A.; Garlanda, C.; Mantovani, A. Cancer-related inflammation, the seventh hallmark of cancer: Links to genetic instability. Carcinogenesis 2009, 30, 1073-1081. [CrossRef]

4. Song, M.; Chan, A.T.; Sun, J. Influence of the Gut Microbiome, Diet, and Environment on Risk of Colorectal Cancer. Gastroenterology 2020, 158, 322-340. [CrossRef]

5. De Santis, S.; Galleggiante, V.; Scandiffio, L.; Liso, M.; Sommella, E.; Sobolewski, A.; Spilotro, V.; Pinto, A.; Campiglia, P.; Serino, G.; et al. Secretory Leukoprotease Inhibitor (Slpi) Expression Is Required for Educating Murine Dendritic Cells Inflammatory Response Following Quercetin Exposure. Nutrients 2017, 9, 706. [CrossRef] 
6. Cariello, M.; Contursi, A.; Gadaleta, R.M.; Piccinin, E.; De Santis, S.; Piglionica, M.; Spaziante, A.F.; Sabba, C.; Villani, G.; Moschetta, A. Extra-Virgin Olive Oil from Apulian Cultivars and Intestinal Inflammation. Nutrients 2020, 12, 1084. [CrossRef]

7. De Santis, S.; Clodoveo, M.L.; Cariello, M.; D'Amato, G.; Franchini, C.; Faienza, M.F.; Corbo, F. Polyphenols and obesity prevention: Critical insights on molecular regulation, bioavailability and dose in preclinical and clinical settings. Crit. Rev. Food Sci. Nutr. 2020, 1-23. [CrossRef]

8. Piccinin, E.; Cariello, M.; De Santis, S.; Ducheix, S.; Sabba, C.; Ntambi, J.M.; Moschetta, A. Role of Oleic Acid in the Gut-Liver Axis: From Diet to the Regulation of Its Synthesis via Stearoyl-CoA Desaturase 1 (SCD1). Nutrients 2019, 11, 2283. [CrossRef]

9. De Santis, S.; Cariello, M.; Piccinin, E.; Sabba, C.; Moschetta, A. Extra Virgin Olive Oil: Lesson from Nutrigenomics. Nutrients 2019, 11, 2085. [CrossRef]

10. Kolodziejczyk, A.A.; Zheng, D.; Elinav, E. Diet-microbiota interactions and personalized nutrition. Nat. Rev. Microbiol. 2019, 17, 742-753. [CrossRef]

11. Baquero, F.; Nombela, C. The microbiome as a human organ. Clin. Microbiol. Infect. 2012, 18, 2-4. [CrossRef] [PubMed]

12. Kho, Z.Y.; Lal, S.K. The Human Gut Microbiome-A Potential Controller of Wellness and Disease. Front. Microbiol. 2018, 9, 1835. [CrossRef] [PubMed]

13. Wilkins, L.J.; Monga, M.; Miller, A.W. Defining Dysbiosis for a Cluster of Chronic Diseases. Sci. Rep. 2019, 9, 12918. [CrossRef] [PubMed]

14. Montalban-Arques, A.; Scharl, M. Intestinal microbiota and colorectal carcinoma: Implications for pathogenesis, diagnosis, and therapy. EBioMedicine 2019, 48, 648-655. [CrossRef]

15. Fong, W.; Li, Q.; Yu, J. Gut microbiota modulation: A novel strategy for prevention and treatment of colorectal cancer. Oncogene 2020, 39, 4925-4943. [CrossRef]

16. Gao, Z.; Guo, B.; Gao, R.; Zhu, Q.; Qin, H. Microbiota disbiosis is associated with colorectal cancer. Front. Microbiol. 2015, 6, 20. [CrossRef]

17. Marchesi, J.R.; Dutilh, B.E.; Hall, N.; Peters, W.H.; Roelofs, R.; Boleij, A.; Tjalsma, H. Towards the human colorectal cancer microbiome. PLOS ONE 2011, 6, e20447. [CrossRef]

18. Wu, S.; Rhee, K.J.; Albesiano, E.; Rabizadeh, S.; Wu, X.; Yen, H.R.; Huso, D.L.; Brancati, F.L.; Wick, E.; McAllister, F.; et al. A human colonic commensal promotes colon tumorigenesis via activation of T helper type $17 \mathrm{~T}$ cell responses. Nat. Med. 2009, 15, 1016-1022. [CrossRef]

19. Goodwin, A.C.; Destefano Shields, C.E.; Wu, S.; Huso, D.L.; Wu, X.; Murray-Stewart, T.R.; Hacker-Prietz, A.; Rabizadeh, S.; Woster, P.M.; Sears, C.L.; et al. Polyamine catabolism contributes to enterotoxigenic Bacteroides fragilis-induced colon tumorigenesis. Proc. Natl. Acad. Sci. USA 2011, 108, 15354-15359. [CrossRef]

20. Wu, S.; Morin, P.J.; Maouyo, D.; Sears, C.L. Bacteroides fragilis enterotoxin induces c-Myc expression and cellular proliferation. Gastroenterology 2003, 124, 392-400. [CrossRef]

21. Rubinstein, M.R.; Wang, X.; Liu, W.; Hao, Y.; Cai, G.; Han, Y.W. Fusobacterium nucleatum promotes colorectal carcinogenesis by modulating E-cadherin/beta-catenin signaling via its FadA adhesin. Cell Host Microbe 2013, 14, 195-206. [CrossRef]

22. Prorok-Hamon, M.; Friswell, M.K.; Alswied, A.; Roberts, C.L.; Song, F.; Flanagan, P.K.; Knight, P.; Codling, C.; Marchesi, J.R.; Winstanley, C.; et al. Colonic mucosa-associated diffusely adherent afaC+Escherichia coli expressing lpfA and pks are increased in inflammatory bowel disease and colon cancer. Gut 2014, 63, 761-770. [CrossRef]

23. Gagniere, J.; Raisch, J.; Veziant, J.; Barnich, N.; Bonnet, R.; Buc, E.; Bringer, M.A.; Pezet, D.; Bonnet, M. Gut microbiota imbalance and colorectal cancer. World J. Gastroenterol. 2016, 22, 501-518. [CrossRef]

24. Wang, T.; Cai, G.; Qiu, Y.; Fei, N.; Zhang, M.; Pang, X.; Jia, W.; Cai, S.; Zhao, L. Structural segregation of gut microbiota between colorectal cancer patients and healthy volunteers. ISME J. 2012, 6, 320-329. [CrossRef]

25. Vogtmann, E.; Hua, X.; Zeller, G.; Sunagawa, S.; Voigt, A.Y.; Hercog, R.; Goedert, J.J.; Shi, J.; Bork, P.; Sinha, R. Colorectal Cancer and the Human Gut Microbiome: Reproducibility with Whole-Genome Shotgun Sequencing. PLoS ONE 2016, 11, e0155362. [CrossRef] [PubMed]

26. Yu, J.; Feng, Q.; Wong, S.H.; Zhang, D.; Liang, Q.Y.; Qin, Y.; Tang, L.; Zhao, H.; Stenvang, J.; Li, Y.; et al. Metagenomic analysis of faecal microbiome as a tool towards targeted non-invasive biomarkers for colorectal cancer. Gut 2017, 66, 70-78. [CrossRef]

27. Tjalsma, H.; Boleij, A.; Marchesi, J.R.; Dutilh, B.E. A bacterial driver-passenger model for colorectal cancer: Beyond the usual suspects. Nat. Rev. Microbiol. 2012, 10, 575-582. [CrossRef]

28. Boleij, A.; Hechenbleikner, E.M.; Goodwin, A.C.; Badani, R.; Stein, E.M.; Lazarev, M.G.; Ellis, B.; Carroll, K.C.; Albesiano, E.; Wick, E.C.; et al. The Bacteroides fragilis toxin gene is prevalent in the colon mucosa of colorectal cancer patients. Clin. Infect. Dis. 2015, 60, 208-215. [CrossRef]

29. Bonnet, M.; Buc, E.; Sauvanet, P.; Darcha, C.; Dubois, D.; Pereira, B.; Dechelotte, P.; Bonnet, R.; Pezet, D.; Darfeuille-Michaud, A. Colonization of the human gut by E. coli and colorectal cancer risk. Clin. Cancer Res. 2014, 20, 859-867. [CrossRef]

30. Yachida, S.; Mizutani, S.; Shiroma, H.; Shiba, S.; Nakajima, T.; Sakamoto, T.; Watanabe, H.; Masuda, K.; Nishimoto, Y.; Kubo, M.; et al. Metagenomic and metabolomic analyses reveal distinct stage-specific phenotypes of the gut microbiota in colorectal cancer. Nat. Med. 2019, 25, 968-976. [CrossRef]

31. Nakatsu, G.; Li, X.; Zhou, H.; Sheng, J.; Wong, S.H.; Wu, W.K.; Ng, S.C.; Tsoi, H.; Dong, Y.; Zhang, N.; et al. Gut mucosal microbiome across stages of colorectal carcinogenesis. Nat. Commun. 2015, 6, 8727. [CrossRef] 
32. Feng, Q.; Liang, S.; Jia, H.; Stadlmayr, A.; Tang, L.; Lan, Z.; Zhang, D.; Xia, H.; Xu, X.; Jie, Z.; et al. Gut microbiome development along the colorectal adenoma-carcinoma sequence. Nat. Commun. 2015, 6, 6528. [CrossRef]

33. Roy, S.; Trinchieri, G. Microbiota: A key orchestrator of cancer therapy. Nat. Rev. Cancer 2017, 17, 271-285. [CrossRef]

34. Eiseman, B.; Silen, W.; Bascom, G.S.; Kauvar, A.J. Fecal enema as an adjunct in the treatment of pseudomembranous enterocolitis. Surgery 1958, 44, 854-859.

35. Saus, E.; Iraola-Guzman, S.; Willis, J.R.; Brunet-Vega, A.; Gabaldon, T. Microbiome and colorectal cancer: Roles in carcinogenesis and clinical potential. Mol. Aspects Med. 2019, 69, 93-106. [CrossRef]

36. Su, L.K.; Kinzler, K.W.; Vogelstein, B.; Preisinger, A.C.; Moser, A.R.; Luongo, C.; Gould, K.A.; Dove, W.F. Multiple intestinal neoplasia caused by a mutation in the murine homolog of the APC gene. Science 1992, 256, 668-670. [CrossRef]

37. Li, L.; Li, X.; Zhong, W.; Yang, M.; Xu, M.; Sun, Y.; Ma, J.; Liu, T.; Song, X.; Dong, W.; et al. Gut microbiota from colorectal cancer patients enhances the progression of intestinal adenoma in Apc(min/+) mice. EBioMedicine 2019, 48, 301-315. [CrossRef]

38. Okayasu, I.; Hatakeyama, S.; Yamada, M.; Ohkusa, T.; Inagaki, Y.; Nakaya, R. A novel method in the induction of reliable experimental acute and chronic ulcerative colitis in mice. Gastroenterology 1990, 98, 694-702. [CrossRef]

39. Zhan, Y.; Chen, P.J.; Sadler, W.D.; Wang, F.; Poe, S.; Nunez, G.; Eaton, K.A.; Chen, G.Y. Gut microbiota protects against gastrointestinal tumorigenesis caused by epithelial injury. Cancer Res. 2013, 73, 7199-7210. [CrossRef]

40. De Santis, S.; Verna, G.; Serino, G.; Armentano, R.; Cavalcanti, E.; Liso, M.; Dicarlo, M.; Coletta, S.; Mastronardi, M.; Lippolis, A.; et al. Winnie-APC(Min/+) Mice: A Spontaneous Model of Colitis-Associated Colorectal Cancer Combining Genetics and Inflammation. Int. J. Mol. Sci. 2020, 21, 2972. [CrossRef]

41. Heazlewood, C.K.; Cook, M.C.; Eri, R.; Price, G.R.; Tauro, S.B.; Taupin, D.; Thornton, D.J.; Png, C.W.; Crockford, T.L.; Cornall, R.J.; et al. Aberrant mucin assembly in mice causes endoplasmic reticulum stress and spontaneous inflammation resembling ulcerative colitis. PLoS Med. 2008, 5, e54. [CrossRef] [PubMed]

42. Liso, M.; De Santis, S.; Verna, G.; Dicarlo, M.; Calasso, M.; Santino, A.; Gigante, I.; Eri, R.; Raveenthiraraj, S.; Sobolewski, A.; et al. A Specific Mutation in Muc2 Determines Early Dysbiosis in Colitis-Prone Winnie Mice. Inflamm. Bowel Dis. 2020, 26, 546-556. [CrossRef] [PubMed]

43. Nalbantoglu, I.; Blanc, V.; Davidson, N.O. Characterization of Colorectal Cancer Development in Apc (min/+) Mice. Methods Mol. Biol. 2016, 1422, 309-327. [PubMed]

44. Shoemaker, A.R.; Gould, K.A.; Luongo, C.; Moser, A.R.; Dove, W.F. Studies of neoplasia in the Min mouse. Biochim. Biophys. Acta 1997, 1332, F25-F48.

45. Tilg, H.; Adolph, T.E.; Gerner, R.R.; Moschen, A.R. The Intestinal Microbiota in Colorectal Cancer. Cancer Cell 2018, 33, 954-964. [CrossRef]

46. Ottman, N.; Huuskonen, L.; Reunanen, J.; Boeren, S.; Klievink, J.; Smidt, H.; Belzer, C.; de Vos, W.M. Characterization of Outer Membrane Proteome of Akkermansia muciniphila Reveals Sets of Novel Proteins Exposed to the Human Intestine. Front. Microbiol. 2016, 7, 1157. [CrossRef]

47. Kang, C.S.; Ban, M.; Choi, E.J.; Moon, H.G.; Jeon, J.S.; Kim, D.K.; Park, S.K.; Jeon, S.G.; Roh, T.Y.; Myung, S.J.; et al. Extracellular vesicles derived from gut microbiota, especially Akkermansia muciniphila, protect the progression of dextran sulfate sodiuminduced colitis. PLoS ONE 2013, 8, e76520. [CrossRef]

48. Sobhani, I.; Tap, J.; Roudot-Thoraval, F.; Roperch, J.P.; Letulle, S.; Langella, P.; Corthier, G.; Tran Van Nhieu, J.; Furet, J.P. Microbial dysbiosis in colorectal cancer (CRC) patients. PLoS ONE 2011, 6, e16393. [CrossRef]

49. Mori, G.; Rampelli, S.; Orena, B.S.; Rengucci, C.; De Maio, G.; Barbieri, G.; Passardi, A.; Casadei Gardini, A.; Frassineti, G.L.; Gaiarsa, S.; et al. Shifts of Faecal Microbiota During Sporadic Colorectal Carcinogenesis. Sci. Rep. 2018, 8, 10329. [CrossRef]

50. Sobhani, I.; Bergsten, E.; Couffin, S.; Amiot, A.; Nebbad, B.; Barau, C.; de'Angelis, N.; Rabot, S.; Canoui-Poitrine, F.; Mestivier, D.; et al. Colorectal cancer-associated microbiota contributes to oncogenic epigenetic signatures. Proc. Natl. Acad. Sci. USA 2019, 116, 24285-24295. [CrossRef]

51. Feinberg, A.P.; Koldobskiy, M.A.; Gondor, A. Epigenetic modulators, modifiers and mediators in cancer aetiology and progression. Nat. Rev. Genet. 2016, 17, 284-299. [CrossRef] [PubMed]

52. Wong, J.J.; Hawkins, N.J.; Ward, R.L. Colorectal cancer: A model for epigenetic tumorigenesis. Gut 2007, 56, 140-148. [CrossRef] [PubMed]

53. Shuwen, H.; Miao, D.; Quan, Q.; Wei, W.; Zhongshan, Z.; Chun, Z.; Xi, Y. Protective effect of the "food-microorganism-SCFAs" axis on colorectal cancer: From basic research to practical application. J. Cancer Res. Clin. Oncol. 2019, 145, 2169-2197. [CrossRef]

54. O'Keefe, S.J. Diet, microorganisms and their metabolites, and colon cancer. Nat. Rev. Gastroenterol. Hepatol. 2016, 13, 691-706. [CrossRef]

55. Parada Venegas, D.; De la Fuente, M.K.; Landskron, G.; Gonzalez, M.J.; Quera, R.; Dijkstra, G.; Harmsen, H.J.M.; Faber, K.N.; Hermoso, M.A. Corrigendum: Short Chain Fatty Acids (SCFAs)-Mediated Gut Epithelial and Immune Regulation and Its Relevance for Inflammatory Bowel Diseases. Front. Immunol. 2019, 10, 1486. [CrossRef] [PubMed]

56. De Santis, S.; Cavalcanti, E.; Mastronardi, M.; Jirillo, E.; Chieppa, M. Nutritional Keys for Intestinal Barrier Modulation. Front. Immunol. 2015, 6, 612. [CrossRef] [PubMed]

57. Vacca, M.; Celano, G.; Calabrese, F.M.; Portincasa, P.; Gobbetti, M.; De Angelis, M. The Controversial Role of Human Gut Lachnospiraceae. Microorganisms 2020, 8, 573. [CrossRef] [PubMed] 
58. McEneany, V.L.; Coyne, M.J.; Chatzidaki-Livanis, M.; Comstock, L.E. Acquisition of MACPF domain-encoding genes is the main contributor to LPS glycan diversity in gut Bacteroides species. ISME J. 2018, 12, 2919-2928. [CrossRef] [PubMed]

59. Angrisano, T.; Pero, R.; Peluso, S.; Keller, S.; Sacchetti, S.; Bruni, C.B.; Chiariotti, L.; Lembo, F. LPS-induced IL-8 activation in human intestinal epithelial cells is accompanied by specific histone $\mathrm{H} 3$ acetylation and methylation changes. BMC Microbiol. 2010, 10, 172. [CrossRef] [PubMed]

60. Wu, Y.; Li, R.W.; Huang, H.; Fletcher, A.; Yu, L.; Pham, Q.; Yu, L.; He, Q.; Wang, T.T.Y. Inhibition of Tumor Growth by Dietary Indole-3-Carbinol in a Prostate Cancer Xenograft Model May Be Associated with Disrupted Gut Microbial Interactions. Nutrients 2019, 11, 467. [CrossRef]

61. Zagato, E.; Pozzi, C.; Bertocchi, A.; Schioppa, T.; Saccheri, F.; Guglietta, S.; Fosso, B.; Melocchi, L.; Nizzoli, G.; Troisi, J.; et al. Endogenous murine microbiota member Faecalibaculum rodentium and its human homologue protect from intestinal tumour growth. Nat. Microbiol. 2020, 5, 511-524. [CrossRef] [PubMed]

62. Kostic, A.D.; Chun, E.; Robertson, L.; Glickman, J.N.; Gallini, C.A.; Michaud, M.; Clancy, T.E.; Chung, D.C.; Lochhead, P.; Hold, G.L.; et al. Fusobacterium nucleatum potentiates intestinal tumorigenesis and modulates the tumor-immune microenvironment. Cell Host Microbe 2013, 14, 207-215. [CrossRef] [PubMed]

63. Liso, M.; De Santis, S.; Scarano, A.; Verna, G.; Dicarlo, M.; Galleggiante, V.; Campiglia, P.; Mastronardi, M.; Lippolis, A.; Vacca, M.; et al. A Bronze-Tomato Enriched Diet Affects the Intestinal Microbiome under Homeostatic and Inflammatory Conditions. Nutrients 2018, 10, 1862. [CrossRef] [PubMed]

64. De Angelis, M.; Ferrocino, I.; Calabrese, F.M.; De Filippis, F.; Cavallo, N.; Siragusa, S.; Rampelli, S.; Di Cagno, R.; Rantsiou, K.; Vannini, L.; et al. Diet influences the functions of the human intestinal microbiome. Sci. Rep. 2020, 10, 4247. [CrossRef] [PubMed]

65. Scarano, A.; Butelli, E.; De Santis, S.; Cavalcanti, E.; Hill, L.; De Angelis, M.; Giovinazzo, G.; Chieppa, M.; Martin, C.; Santino, A. Combined Dietary Anthocyanins, Flavonols, and Stilbenoids Alleviate Inflammatory Bowel Disease Symptoms in Mice. Front. Nutr. 2017, 4, 75. [CrossRef]

66. Klindworth, A.; Pruesse, E.; Schweer, T.; Peplies, J.; Quast, C.; Horn, M.; Glockner, F.O. Evaluation of general 16S ribosomal RNA gene PCR primers for classical and next-generation sequencing-based diversity studies. Nucleic Acids Res. 2013, 41, e1. [CrossRef]

67. Wang, Q.; Garrity, G.M.; Tiedje, J.M.; Cole, J.R. Naive Bayesian classifier for rapid assignment of rRNA sequences into the new bacterial taxonomy. Appl. Environ. Microbiol. 2007, 73, 5261-5267. [CrossRef]

68. Gondalia, S.V.; Palombo, E.A.; Knowles, S.R.; Cox, S.B.; Meyer, D.; Austin, D.W. Molecular characterisation of gastrointestinal microbiota of children with autism (with and without gastrointestinal dysfunction) and their neurotypical siblings. Autism Res. 2012, 5, 419-427. [CrossRef]

69. De Angelis, M.; Piccolo, M.; Vannini, L.; Siragusa, S.; De Giacomo, A.; Serrazzanetti, D.I.; Cristofori, F.; Guerzoni, M.E.; Gobbetti, M.; Francavilla, R. Fecal microbiota and metabolome of children with autism and pervasive developmental disorder not otherwise specified. PLoS ONE 2013, 8, e76993. [CrossRef]

70. Finegold, S.M.; Dowd, S.E.; Gontcharova, V.; Liu, C.; Henley, K.E.; Wolcott, R.D.; Youn, E.; Summanen, P.H.; Granpeesheh, D.; Dixon, D.; et al. Pyrosequencing study of fecal microflora of autistic and control children. Anaerobe 2010, 16, 444-453. [CrossRef] [PubMed]

71. Serino, M.; Luche, E.; Gres, S.; Baylac, A.; Berge, M.; Cenac, C.; Waget, A.; Klopp, P.; Iacovoni, J.; Klopp, C.; et al. Metabolic adaptation to a high-fat diet is associated with a change in the gut microbiota. Gut 2012, 61, 543-553. [CrossRef] [PubMed] 